\title{
UNA CONCEPCIÓN TRANSDUCTIVA DEL CAMBIO SOCIAL: DISCAPACIDAD, AGENTES, CUERPOS Y EMOCIONES ${ }^{1}$
}

\author{
Miguel A. V. Ferreira ${ }^{2}$ \\ Universidad Complutense de Madrid
}

\begin{abstract}
Resumen.- El pensamiento sociológico, desde sus inicios, está atrapado en las grandes dicotomías que fundaron el ideario ilustrado. Sujeto y objeto, como delimitaciones primarias de las mismas, condujeron a todas las demás. Entre ellas está la que ya inaugurara Comte: la estática y la dinámica social, la estructura y el cambio. Ahora bien, el cambio social, como ámbito de reflexión, entrecruza dicha dicotomía fundacional con otra, contradictoria e inconjugable con la misma: la del cambio como fenómeno de conjunto (o sea, estructural), frente a la agencia, a la acción social como fenómeno singular. Dicha contradicción da pie a rereflexionar sobre los parámetros epistemológicos que hemos heredado. Proponemos, frente a esta herencia racionalista y dicotómica, una regeneración epistemológica que parte de un "principio procesual": el cambio es el "ontos" y de su permanente irresolución resulta nuestra existencia; el "ser" es una ficción filosófica; por añadidura, el "individuo" como categoría política, en primera instancia, y sociológica en segunda. El error ha supuesto la pérdida de la persona humana, en su integridad constitutiva, y en lo que socialmente (lo cual es una reducción) la conforma. Se torna necesario rescatar a la persona de entre esas categorías cosificadas (sujeto, individuo y ciudadano) y restituirla en su verdadera condición. Para ello, y en contra del "sujeto", hay que llevar a primer plano el cuerpo (la animalidad biológica socialmente conformada y conformadora) y las emociones (el irracional catalizador de la racionalidad). Unas personas "excedentes" como tales aunque deficitarias para las categorías que las encapsulan son las personas con discapacidad. Punto de partida para una reconfiguración epistemológica: la constitutiva condición discapacitada y discapacitante del mundo en el que vivimos, yermo (en lo formal) de emociones y de cuerpos. Llegó la hora, quizá, de reavivar el inconsciente colectivo reprimido.
\end{abstract}

Palabras clave.- Cambio social, modernidad, cuerpo, emociones, discapacidad, transductividad

${ }^{1}$ El presente texto se propone en formato de ensayo; dadas las premuras de tiempo de la ocasión que lo suscita (una oposición para una plaza de Profesor Titular de Universidad, celebrada el 19 de julio de 2011) y la necesidad, vital, del autor de cumplir adecuadamente, al margen de la formalidad de la misma, con los requisitos exigidos, se ha optado por un texto en el que se omiten casi todas las referencias bibliográficas utilizadas. Ruego disculpas al/a la lector/a del presente texto y me comprometo a enmendar en un futuro, espero que cercano, esa carencia que atenta flagrantemente contra el principio de "autoridad" (la auctoritas escolástica tan, a la par, denostada como fielmente seguida por Pierre Bourdieu; autor que tiene parte substancial en lo que aquí se va a narrar). En todo caso, considerando que puede ser de interés y, por ello, lo someto a "juicio público".

${ }^{2}$ Profesor Titular de Universidad en el Dpto. de Cambio Social de la UCM. Director de la Revista Intersticios (www.intersticios.es); Coordinador Internacional de la Red Iberoamericana de Estudios Sociales sobre Discapacidad (RIESDIS); presidente de la Asociación Española de Sociología de la Discapacidad (ASESDIS: www.asesdis.es). Entre sus publicaciones, cabe señalar: Por una sociología de la discapacidad (coord.) (Política y Sociedad, 47 (1), monográfico, 2010); "De la minus-valía a la diversidad funcional: un nuevo marco teóricometodológico (ibíd.); "Discapacidad, globalidad y educación: ¿una nueva "política del cuerpo"? (RELACES, 2011); "La epistemología como praxis en tiempos de crisis: subversiones y/o perversiones de las convenciones normativas" (Intersticios 5(1), 2011); "Desde la dis-capacidad hacia la diversidad funcional: un ejercicio de dis-normalización" (RIS, 68(2), 2010); "Lo social como proceso: la transductividad ontogenética de las prácticas sociales" (Nómadas 22, 2009); "Discapacidad, exclusión social y nuevas tecnologíad de la información" (Política y Sociedad 46 (1 y 2), 2009); "Una aproximación sociológica a la discapacidad desde el modelo social: apuntes caracteriológicos" (REIS 124, 2008); la vida antes del laboratorio: la construcción de los constructores de hechos científicos (CIS, 2007). 
Abstract.- From its first steps, sociological thinkingi prisoner of Ilustration mape dicotomies. Subject and object as its primarly mannifestation, and Comte proposal, distinguishing "static" form "dinamic" as a first enunciation; structure against change. But social change, as an space of reflection, interchange this fundational dicotomie with another one, contradictory with it, the one which places change, as a structural thing, against agency, action, as a singular phemomenum. This contradiction provides the oportunity to re-reflect on our fundational epistemological key criteria. Whe propose a "procesual principle": hcange is the "ontos", and from its permanent irresolution merges our existence; the "being" is a philosofical fiction; in addition, the "individual", as a political categorie, in a first place, and a sociologícal one, in a second plane, also. We have lost the "person" (the human one), in its whoe constitution and in its social conformation. It becomes neccesary to rescue the person from that reified categories (subject, individual and citizen) and replace it in its proper condition. To do that, the body has to be stated in a main place (our animal condition, social conformed and conformational), and, with it, our emotions (the irrational basis of our rationality). Some kind of "persons" who are in conditions to do this are persons with disability (ther are more than a person in their daily life, but are less than a person under the categories putted in cuestion - subject, individual, citizen-). We need an epistemological reconfiguration, that means to change a disabling and disbled world in another one in which body and emotions have the main plece they have to have. Perhaps is now the time to make appear our collective reppressed inconscience.

Key words.- social change, modernity, body, emotions, disability, transductivity

\section{Preámbulo}

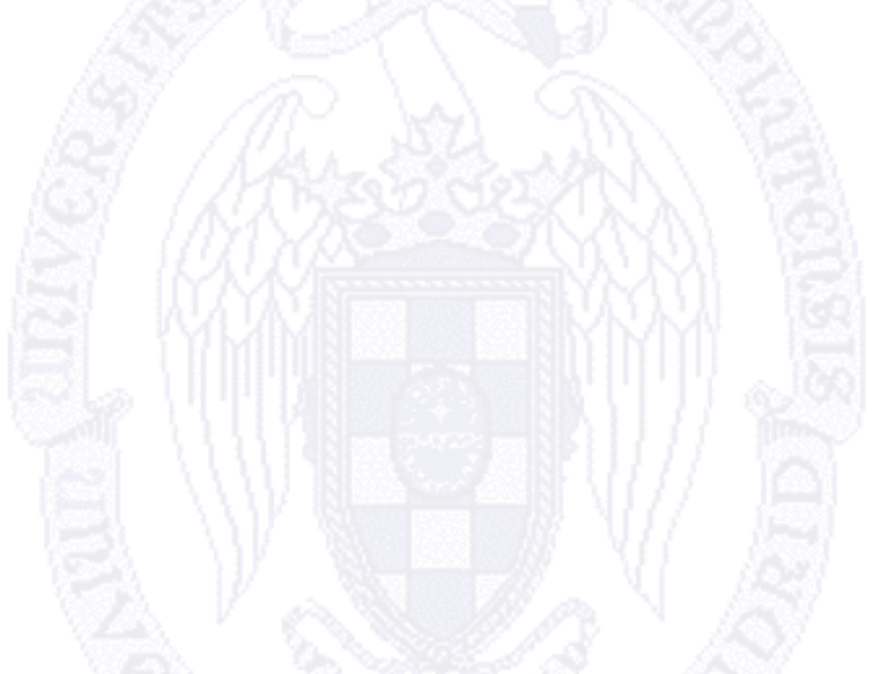

A la hora de fundamentar, o, más propiamente, justificar/ legitimar académicamente, el puesto docente al que aspiraba y que suscita el presente texto, me he visto en la ardua y necesaria tarea de dotar de consistencia e integridad a lo que ya van siendo más de diez años de tarea profesional.

He de confesar que, pese a lo arduo de la misma, la tarea se torna manifiestamente evidente dado el discurrir de esos años. Si algo "fundamenta" un puesto docente es, sin duda, que quien pretenda ocuparlo pueda evidenciar una "mismidad" que, pese a la fragmentaria, transitoria e inestable condición del yo poseído, indique una cierta continuidad en la labor realizada y que la misma se ajuste a lo que el puesto demanda.

La demanda no es cerrada ni impuesta de antemano, puesto que el proyecto docente y el investigador que se tuvieron que presentar para optar a dicho puesto quedaban al arbitrio del candidato. Dado dicho arbitrio, se ha procedido al intento de plasmar en ambos quién es el candidato y por qué lo es (y por qué lo es así y no de otra manera); y, asimismo, a tratar de que, pese a que constituyen elementos distintos y diferenciados dentro de los requerimientos del procedimiento, sean expuestos como partes solidarias e indisociables de un 
proyecto, interés y compromiso vitales. Queda a juicio de los/as lectores/as si el intento tiene un mínimo éxito o no.

Proyecto docente: cambio social. Proyecto investigador: sociología de la discapacidad $^{3}$. ¿Cuál es la conexión entre ambos? En un plano formal, y sin demasiado esfuerzo, es fácilmente demostrable que la discapacidad, abordada desde una perspectiva sociológica, ha significado y es actualmente un proceso de cambio social. Pero en ese plano formal, sinceramente, el autor no se siente satisfecho. Hace falta algo más sólido para llevar a cabo esa pretendida fundamentación/ legitimación/ justificación.

Así que, para llegar a esa conclusión, que pudiera parecer casi evidente en ese plano formal, hace falta un recorrido previo más "sustantivo". Tan sustantivo como que para poder hablar de cambio social o de discapacidad es necesario hacer expreso desde dónde se habla y por qué se habla como se habla y no de otra manera. Es decir, hace falta poner sobre el tapete qué se entiende por "hablar sociológicamente" (en general, y en particular del cambio social y de la discapacidad).

En el caso presente, ello implica recorrer cinco conceptos: reflexividad, autobservación, transductividad, cuerpo y emociones. Si no queda claro, en lo que prosigue, dicho recorrido, el intento habrá sido fallido.

\section{Un marco teórico-metodológico para el análisis del cambio social}

Cuando Comte proponía aquella que entendía como necesaria división de la tarea sociológica en estática y dinámica estaba sentando las bases de una problemática, constitutiva y definitoria de la disciplina, que ha recorrido toda su andadura desde entonces, que no ha sido cerrada y que no lo será, de hecho, nunca.

No era sino la enésima reproducción, en el discurrir del pensamiento europeo occidental, de la dicotomía Parménides/ Heráclito, el ser o el fluir, lo permanente frente a lo mutable. Es una constante de ese pensamiento la elaboración de esquemas de comprensión anclados en dicotomías fundantes y fundacionales; en lo que aquí nos interesa, podemos reducirlas todas a una, en tanto que núcleo de la arquitectura epistemológica que lo sostiene: sujeto y objeto (o lo que es lo mismo: el observador y lo observado; el conocedor y lo conocido; el pensamiento y la realidad). En nuestra tradición cultural, el pensamiento se entiende que lo es de un sujeto sobre un objeto, indicando con ello una operación meramente abstracta, de pura elaboración conceptual, cuyo resultado es una representación formal de una cierta realidad dada (el objeto). El sujeto, sujeto de conocimiento, lo es en tanto que es portador de la

3 El presente texto fue presentado como "Fundamentación teórico-metodológica" de los proyectos docente e investigador para la mencionada plaza de profesor titular de universidad, siendo el primero, el docente, el de una asignatura obligatoria de $2^{\circ}$ curso del nuevo grado en sociología de la Universidad Complutense de Madrid, Cambio Social, y el segundo un proyecto de investigación en curso, en el marco de la línea de investigación ECRP (European Collaborative Research Projects in Social Sciences) de la ESF (European Science Foundation), que trata de indagar, mediante historias de vida, cuál ha sido el impacto efectivo en la experiencia de las personas con discapacidad de todos los cambios normativos que se han dado en las últimas tres décadas y su repercusión en los proyectos de vida de las mismas. 
capacidad inmanente de producir representaciones formales de su(s) objeto(s) de conocimiento.

Esto le resulta evidente y no problemático a la mayoría de los seres humanos formados en esa tradición cultural y de pensamiento (para otras personas, pertenecientes a otras matrices culturales, el planteamiento es sencillamente absurdo - que no les demos crédito, las consideremos situadas en un plano inferior de la escala evolutiva del ser humano o les imputemos la culpa del error forma parte de los muchos débitos que el imperialista mundo occidental tiene con el resto del planeta...-). Forma parte de nuestra herencia "racionalista", de nuestro origen platónico-aristotélico.

Nos hemos acostumbrado a creer que la realidad es una "cosa" dispuesta y predispuesta, en su existencia objetiva, a ser objeto de nuestras operaciones racionales de conocimiento; vivimos en la creencia de que el mundo se compone de infinidad de objetos, materiales e inmateriales, dotados de una naturaleza constitutiva e inmutable y que con susceptibles de aprehensión racional por nuestras capacidades cognitivas. $\mathrm{Y}$, además, presuponemos que todas esas operaciones representativas de conocimiento racional son neutras: una vez realizadas perpetúan la inmutabilidad y desconexión entre sujeto que conoce y objeto conocido. Creemos que al pensar no nos manchamos las manos.

Desde una perspectiva sociológica, y cuando digo "una" ha de quedar bien claro que utilizo un numeral y no un artículo indeterminado, puesto que hay otras posibles, cabe considerar que nos hallamos ante el principal de los errores de la disciplina. ${ }^{4}$ Asumir ese esquema dicotómico fundacional como punto de partida para emprender la tarea del conocimiento sociológico implica marcar un límite definitivo a las posibilidades efectivas de dicho conocimiento; situar una barrera infranqueable de partida... es una renuncia drástica. De hecho, el propio Durkheim hace expresa dicha renuncia cuando declara que cuanto no pueda ser aprehendido mediante observación y contrastación empírica queda fuera de las competencias de la ciencia sociológica; renuncia que implica asumir que la realidad social es demasiado compleja como para poder llegar a un conocimiento pleno de la misma. Efectivamente, cuando dicha realidad se asume como una cosa, y la tarea de su conocimiento una representación abstracta de la cosa, no cabe otra solución.

De modo que tendríamos una estática y una dinámica "coseicas" claramente discernibles mediante operaciones abstractas de representación: cambio social, por un lado, estructura social, por el otro; lo que es cambio no es estructura, y viceversa; delimitado lo uno, lo que resta es lo otro... y viceversa. La familia es estática y es estructura: siempre ha habido familia en las colectividades humanas; pero las modalidades particulares de familia están

${ }^{4}$ Desde otra posible perspectiva sociológica, mayoritaria y portadora de la ortodoxia de la disciplina a fecha actual, el planteamiento racionalista anclado en la dicotomía epistemológica sujeto/ objeto es la única forma adecuada de producir conocimiento "científico". Resulta curioso, cuando menos, que en el país dónde con más naturalidad y fervor ha cuajado dicha perspectiva se descubra con sorpresa en los años 70 del siglo pasado que el conocimiento sociológico puede enriquecerse incorporando una dimensión histórica en sus análisis, que caben análisis sociológicos de carácter genealógico, cuales fueron, precisamente, los de los clásicos de la disciplina, excepción hecha, claro está, de aquél del cual arranca dicha perspectiva. 
sujetas a variabilidad, cultural e histórica, de modo que eso pertenecería a la dinámica, al cambio. El problema, el error, es que se ha presupuesto de antemano, en términos sociológicos qué es la familia, la cosa familia, a conocer sociológicamente, y se ha hecho desde la asunción intuitiva e inconsciente del particular tipo de familia (occidental, burguesa, acomodada, nuclear, atravesada del complejo de Edipo y de la higiene sexual promovida desde los aparatos de saber-poder erigidos por la modernidad, etc.) propio de los "pensadores" (occidentales, burgueses, acomodados, etc.) que la han pensado. La particularidad de la cosa dada y presupuesta, por formar parte de la experiencia vivida y no pensada del pensador que la piensa, ha sido erigida en coseidad generalizable como objeto de pensamiento.

Presupongamos, como alternativa, que la familia es la transposición cultural de un hecho biológico fundamental: la perpetuación de la especie. Estamos biológicamente compelidos a procrear porque somos animales y nos viene dado por esa nuestra biologicidad y animalidad (podemos aceptar esto de partida, como sociólogos, sin problemas porque la ciencia biológica nos dice que así están las cosas; otra opción sería aprender biología para poder poner en cuestión el presupuesto; pero eso nos llevaría demasiado tiempo y esfuerzo). Toda la elaboración normativa, proscriptiva y prescriptiva, en torno a ese "dato" biológico quedaría sujeta a la variabilidad cultural de las distintas colectividades en las que está presente el dato, en todas, y, además, inscrita en el discurrir histórico de las mismas. De este modo, la familia como fenómeno sociológico es a la par e indisociablemente estática y dinámica, no cabe disociar el estatismo de su universal presencia con el dinamismo de sus múltiples formas y modalidades. Y lo que es más importante: partimos de la problematización de la categoría conceptual "familia" y no del presupuesto incuestionado del hecho "familia", hecho particular e impensado del pensador que lo formula como categoría. Hacemos evidente que el sujeto (pensador de la familia) es también objeto (miembro de una familia).

No hemos hecho sino evidenciar eso que, siendo parte habitual de las afirmaciones acerca la naturaleza del saber sociológico y su peculiaridad, acaba quedando relegado al terreno de la mera retórica y no es verdaderamente asumido en todas sus consecuencias: el sociólogo forma parte del mundo que pretende entender; el sujeto de conocimiento sociológico es simultáneamente objeto de dicho conocimiento; no hay posible disociabilidad, en términos epistemológicos, entre sujeto y objeto. Ese esquema dicotómico no es válido para emprender la tarea del conocimiento sociológico.

Por lo tanto, hay que situarse en algún otro punto de partida.

Y de hecho, el problema es que la fundamentación dicotómica de nuestro pensamiento impregna todas las elaboraciones que producimos. Tal es el caso de la disociación entre estática y dinámica. La opción de partida, en consecuencia, pasa por situarse en una posición anti-dicotómica, cuya operación inicial es la problematización de las dicotomías ya instituidas.

Ello es relativamente sencillo en el ámbito del estudio del cambio social si tomamos en consideración una de las definiciones clásicas del mismo: según Nisbet, el cambio social es la sucesión de diferencias en el tiempo en una unidad persistente, donde lo "social" del cambio se refiere a la naturaleza (social y no otra) de dicha unidad. Luego el cambio requiere persistencia para 
darse, o, al menos, para detectarse. No puede definirse el cambio social en oposición y al margen de la perdurabilidad social. Y, en añadidura, está el problema de delimitar de antemano la entidad propiamente social de esa persistencia en la que se da el cambio (digamos que fuera, por ejemplo, la familia...).

Llegados a este punto, nos vemos en la obligación de desembarazarnos, utilizando la expresión de Tilly, del equipamiento intelectual decimonónico heredado y re-elaborar nuestras premisas de partida. Desembarazarnos no implica, ni mucho menos, renunciar a él; se trata de situarlo en perspectiva y acomodarlo a nuestras necesidades. Probablemente significa hacerlo más humano y menos racionalista.

Son los hombres los que hacen la historia, aunque no saben que la están haciendo ni qué historia es la que hacen, decía Marx. La Historia es, por excelencia, el ámbito del cambio social, y las personas son sus protagonistas (dado que a fecha actual la dimensión "género" es de inobviable consideración en cualquier temática sociológica, permítasenos corregir ese involuntario y machista uso del concepto "hombre" por parte de Marx y sustituirlo por el de "persona" - aunque, por otro lado, no dejaba de tener razón Marx, hablando del mundo del que hablaba, de atribuirle el protagonismo exclusivo a los miembros masculinos de la especie-). Quizá, entonces, fuera necesario incorporar una dimensión agencial para la comprensión del cambio social. Es decir, para dar cuenta del cambio social quizá fuera adecuado llegar a comprender cómo las personas con su quehacer contribuyen a que se produzca. Lo cual, además, puede resultar de importancia si se toma en consideración la paradójica circunstancia de que, si bien desde los presupuestos epistemológicos de partida el cambio se opone a la estructura, al revisar la bibliografía sobre la materia se observa que, mayoritariamente, los análisis son estructurales, dado que se analizan procesualidades totales con consistencia como tales sin atención a la singularidad de sus agentes protagonistas (son los problemas de partir de presupuestos dicotómicos: las dicotomías se cruzan y generan inconsistencias. Cambio-dinamismo frente a estructura-estatismo, por un lado, estructura-totalidad frente a agentesingularidad, por el otro).

En resumidas cuentas. Entendemos que una perspectiva sociológica del cambio social ha de partir de la problematización de los esquemas conceptuales dicotómicos de carácter racionalista y que la singularidad de las personas en tanto que agentes sociales debe ser incorporada en ella. Desde este doble presupuesto surgen diversas consideraciones.

\section{Paso preliminar 1: reflexividad frente a objetivismo}

Somos lo que somos, en primera instancia, como consecuencia de todas las transformaciones que la Europa Occidental atravesó en los siglos XVI al XX, por extender el período que puede considerarse que abarca el proceso de transición de las sociedades feudales a las modernas; en segunda instancia, porque ese proceso se nutre de la larga tradición histórica que arranca con la Grecia Clásica (aquella que finalmente erigió a la Filosofía en estandarte de la verdad derrocando a la Mitología). Somos lo que somos porque nos hemos 
nutrido de una matriz cultural erigida en torno a la Racionalidad (el hombre es un ser/animal racional, se nos enseña en la escuela primaria). Este principio de racionalidad se ha hipertrofiado hasta tal punto que ha reducido a cero todas las demás características de las que es portador el ser humano. Y, en última instancia, el propio ser humano se ha perdido de vista tras de esos dos grandes constructos ilustrados, el "individuo" y el "sujeto" (aquí no hablamos de la categoría epistemológica, sino de la atribución a la persona de su condición de tal; ser persona es, básica y fundamentalmente, ser sujeto —e individuo-; obviamente, no se formularon las categorías análogas "sujeta" e "individua"...).

Curiosamente, ese cambio social por excelencia que supuso la transición europea hacia la modernidad fue el desencadenante del pensamiento sociológico; el origen de la disciplina es el del intento de comprensión, por parte de sus primeros formuladores, de dicho cambio. De tal modo que el "objeto" cambio social es, a la par, "sujeto" propiciatorio del pensamiento que tratará de pensarlo; tenemos un sujeto social (constituido por el conjunto de protagonistas que, como agentes sociales, fueron "fabricando" la modernidad) productor del "objeto" intelectual, de las formulaciones teóricas contemporáneas, que trataba de pensarlo. Luego es en origen el cambio social el que desencadena y propicia el tipo de conocimiento que tratará de entender y analizar el cambio social.

Pero además, a fecha actual, vivimos en un mundo que, manteniendo algunos de los fundamentos constitutivos de la modernidad, a partir de los años 70 empezó a dejar de ser lo que había venido siendo según los parámetros propios de dicha modernidad. Estamos inmersos en un proceso de cambio social del que no se podrá dar cuenta plenamente hasta que no emerja aquello que de él haya de surgir: la globalización económica y la hiper-creciente cotidianidad de las tecnologías informáticas dibujan un panorama de más que incierto en el discurrir de los años venideros.

De tal modo que, fundacional y contemporáneamente, el objeto cambio social es, de hecho, la fuente que alimenta el pensamiento sociológico sobre el cambio social; estamos completa e ineludiblemente inmersos en aquello que pretendemos conocer. No cabe, de este modo, asumir esa posición del sujeto transcendental de conocimiento, neutral, ajeno y distante de su objeto de estudio. Comprender el cambio social implica conocernos a nosotros/as mismos/as como agentes sociales implicados/as en él.

Ahora bien, esta implicación, indisociablemente cognitiva y práctica, con el cambio social no nos hace especialmente diferentes de aquellas personas, agentes sociales como nosotros/as, que, en última instancia, son nuestro objeto de estudio como sociólogos/as. Esto sólo indica que, lejos del objetivismo racionalista sobre el que hemos edificado nuestra concepción del saber, somos reflexivos; lo somos porque la cotidianidad práctica de nuestra convivencia es de naturaleza constitutivamente reflexiva.

Para elaborar argumentativamente dicha condición constitutivamente reflexiva, un buen punto de partida es el planteamiento de Cassirer, planteamiento que, justamente, parte de la supresión del principio de racionalidad como determinante fundamental de la condición del ser humano. El ser humano es un ser simbólico, representacional; adquiere su peculiar distinción respecto al resto del mundo animal, no porque sea capaz de pensar racionalmente, sino 
porque puede representarse, de modo abstracto ( $y$ de manera no necesariamente racional: puede ser desiderativa, emotiva, pulsional, absurda... o completamente errónea según premisas racionales) su existencia, el mundo en el que vive y a sí mismo. Es decir, se constituye en su especificidad a partir de una escisión de sí mismo, entre lo que práctica e inmanentemente vive, experimenta, y la representación abstracta y transcendente que de ello se hace. Por lo tanto, el ser humano se constituye como tal en su doble e indisociable condición de actor en el mundo e intérprete de él. $\mathrm{Y}$, de hecho, actúa en virtud de las representaciones que se hace, y es capaz de representarse el mundo, y a sí mismo en él, porque está de manera práctica involucrado en él, porque lo experimenta y ese mundo le nutre de referencias para sus representaciones. Esa es la reflexividad constitutiva de nuestra naturaleza humana que opera en nuestras prácticas e interacciones cotidianas; esa es la fibra, humana, que configura y determina nuestras aptitudes y actitudes sociales ${ }^{5}$.

Puesto que hemos de adoptar una perspectiva sociológica; es decir, asumir humildemente que del ser humano no podemos abarcar toda su integridad constitutiva, sino aquello que nos pueda servir para entenderlo en su condición de partícipe de procesos de convivencia junto con otros seres humanos (y en el caso que nos ocupa, no lo olvidemos, para la comprensión del cambio social), aceptando el presupuesto de esa escisión representacional/ práctica como

\footnotetext{
${ }^{5}$ Cabe añadir que, según Cassirer, una vez adquirida esa capacidad representacional, el ser humano tomará conciencia de la muerte: en medio de toda la incertidumbre y contingencia que caracterizan su existencia, se da cuenta de que hay una única verdad irrefutable, un único hecho cierto que la caracteriza; que un día esa vida terminará. La única verdad humana de la vida es el incontestable e ineludible fin de la misma. De ahí surgirían todas las elaboraciones culturales ancladas en principios religiosos cuyo objetivo sería paliar la angustia del "descubrimiento" y prometer una continuidad de la existencia más allá de la muerte; la noción transcendente del sujeto cognoscente, como categoría definitoria del ser humano perpetuable en el tiempo más allá de las existencias singulares, no vendría sino a ser un substituto, racionalizado y laicizado, de la noción de Dios como entidad portadora de la capacidad de perpetuar la vida más allá de la muerte. Algo que, sin duda, no les gustaría descubrir a los adeptos del racionalismo positivista. Aunque, ciertamente, esto ya nos viene de antaño, pues, según Platón, en el mundo de las ideas (el auténtico y no este miserable de la precaria existencia material humana) la verdad, el bien y la belleza son coincidentes en naturaleza (no cabe conocimiento/razón sin virtud moral y estética ajustada al canon: los pecadores y los feos no son portadores de conocimiento; el Dios-Sol, fuente de la luz que nos permite ver las sombras en la pared de la caverna, nos otorga tanto el don del conocimiento como los de la salvación del alma y del cuerpo; este concepto, el cuerpo, emerge ya aquí implícito y eludido, pero central en su condición determinante de nuestra existencia; abundaremos en ello más adelante). En todo caso, como bien nos recuerda Castells, en nuestra contemporaneidad parece ser que esta razón primaria para nuestra conformación cultural como seres humanos, la muerte, ha llegado a ser tan problemática (quizá porque la ciencia médica se ha erigido en uno de los principales baluartes del saber científico que avala con sus verdades en torno a la salud las arbitrarias decisiones de los poderes políticos y, pese a ello, aún no ha logrado librarnos de ella, de la muerte) que, por primera vez en los siglos de historia que nos preceden, hemos decidido negarla. Un mundo en el que la gente niega la muerte y actúa creyendo, realmente, que ésta no llegará (y doy pleno crédito a la afirmación de Castells, visto el panorama mediático y publicitario que nos engulle) es, sin duda, menos humano que uno en el que la angustia de la muerte sea ingrediente central de nuestras preocupaciones. Tómese esto como un indicador específico para la consideración del ya apuntado proceso contemporáneo de cambio social en el que estamos inmersos.
} 
definitoria de nuestra constitución humana, habremos de considerar las dimensiones sociales que la misma conlleva.

Si como seres humanos somos reflexivos, en nuestra coexistencia social eso debe tener repercusiones; es decir, ha de haber dimensiones sociales de esa nuestra constitutiva naturaleza reflexiva. Aquí, dos referencias clásicas nos resultan de tremenda utilidad: Merton y Garfinkel; las consecuencias imprevistas de la acción social ( $y$, en añadidura, la lógica de las profecías autocumplidas) y la entidad eminentemente práctica de las representaciones que las personas aplican en sus quehaceres cotidianos. Si una determinada representación de la realidad es asumida por mucha gente, ello puede propiciar que, fruto de una acción colectiva, la realidad se transforme para ajustarse a la misma; si un conjunto de personas está sometido a la regularidad de un determinado espacio, condicionante, institucional, esas personas lograrán actuar eficientemente porque, sin ser conscientes de ello, estarán aplicando en sus prácticas ciertos consensos representacionales. Dicho de otra manera: como agentes sociales armonizamos nuestra capacidad representacional con la de las demás personas con las que convivimos para, digámoslo así, que todo funcione. Somos socialmente reflexivos porque, como seres humanos, lo somos constitutivamente, y ello, hemos de insistir, no implica aplicación alguna de criterios ni aptitudes de racionalidad; basta con que seamos capaces de dar sentido al mundo, implicados material y prácticamente en él, y tener en consideración a las personas con las que nos relacionamos, capaces a su vez de hacer lo mismo (esto es, atribuir un sentido y ser competentes de manera práctica).

Así pues, para comprender, sociológicamente, los mecanismos agenciales involucrados en los procesos de cambio social, no podemos situarnos en la perspectiva del "privilegiado" observador que, por encima de las capacidades cognitivas de aquellos/as a quienes observa, está en condiciones de producir una representación, un sentido, más fiel del que producen los/as propios/as protagonistas de lo representado. Habremos de asumir nuestra condicionalidad como agentes sociales y hacer expresos/as los sentidos y prácticas que modulan nuestra capacidad de dar sentido al mundo; pues esa operación es, precisamente, la práctica que nos define como sociólogos/as.

¿Qué sino significa La ética protestante y el espíritu del capitalismo? Max Weber, actor partícipe de ese proceso de modernización que, al mismo tiempo, quería entender en sus claves definitorias. A mi modo de ver, es un ejercicio reflexivo de difícil emulación en el que el "objeto" capitalismo es considerado desde el sentido atribuido por los agentes sociales a la práctica económica en la que se hallan involucrados: el capitalismo es la práctica resultante de la angustia humana propiciada por el principio calvinista de la predestinación y la obligación moral adquirida en el quehacer mundano de lo económico adquiere su eficiencia de la incuestionable creencia en dicho principio y la agónica búsqueda de signos que evidencien que se forma parte de los predestinados a la salvación.

¿Y qué decir de, por ejemplo, de Los manuscritos económico-filosóficos? Karl Marx, a su vez, actor e intérprete de ese proceso de transformación, inmerso, vivencialmente, en la praxis revolucionaria: El capital, que es una monumental obra intelectual de desmenuzamiento de la lógica funcional y estructural de la 
economía capitalista, es lo que es porque la intención de su autor no era, fundamentalmente, el conocimiento de dicha lógica, sino la destrucción de la criatura, la revolución.

Bien es cierto que ambos autores gozaban de todos los privilegios propios de la época para poder dedicarse, de un modo u otro, a la erudita labor de teorizar respecto al mundo en el que vivían, en tanto que la mayor parte de la población humana, por ese entonces, sólo podía aplicar su constitutiva condición reflexiva a la labores de supervivencia; en un mundo, además, en el que la voluntad divina todavía tenía el privilegio de ser principio regulador de los sentidos asociados a su existencia y la Razón llustrada, ya gestada y conformada previamente, sólo estaba en posesión de élites minoritarias. El sujeto de razón era, bien un aristócrata acomodado a los nuevos tiempos, bien un miembro de la nueva clase social que lideraba la transformación, la burguesía (la alta, evidentemente). Sólo mucho más tarde se acabaría imponiendo con verdadera pretensión de universalidad dicha categoría atribuida al ser humano, como bien nos recuerda Luhmann al señalar que no fue posible una constitución funcional de los sistemas sociales hasta que se implantó el principio de la educación universal y, a través de él, la inculcación generalizada a todas las poblaciones, sin distinción de condición ni procedencia social, de esos referentes significacionales elaborados por la llustración, los grandes, y pequeños, constructos de la Razón.

En todo caso, emerge ya esa nuestra condición constitutivamente reflexiva, como seres humanos y como agentes sociales, en las formulaciones de los clásicos, si es que se está dispuesto a, y en condiciones de realizar una determinada lectura de las mismas. Incluso el propio Durkheim, al cual cabe achacar el pecado original de incorporar a la ciencia sociológica los principios fundamentales de ese racionalismo ilustrado anclado en la lógica analítica de las dicotomías al postular la necesidad de una ciencia "positiva" de lo social amparada en los criterios metodológicos de las ciencias naturales empíricas surgidas y proliferantes al amparo del paradigma newtoniano. Todo cuanto planteaba Durkheim era resultado del profundo compromiso que el autor, como agente social partícipe de ese proceso de transformación que trataba de entender, tenía con el mundo en el que vivía y de su sincera voluntad de mejora del mismo. Otra cuestión es que, a diferencia de Weber y Marx, sus aportaciones no incorporaran una dimensión, en cuanto a fundamentos, histórica o genealógica.

El gran cambio social que marca la transición hacia el tipo de mundo que hemos heredado, aún cuando, insisto, a fecha actual está operando otro gran proceso de transformación que acabará marcando una ruptura con ese mundo, ese cambio social por antonomasia, es el que propicia el surgimiento de la disciplina académica que tendrá por objetivo, entre otros muchos, la comprensión del cambio social: el "hecho" produce al "pensamiento" que tratará de pensarlo. Pero esto, no dicho en abstracto, sino en términos de unas personas concretas (Marx, Weber, Durkheim) que, como tales, eran agentes sociales involucrados en dicho proceso de transformación, portadores, como todo ser humano, de esa condición reflexiva de nuestra existencia. He aquí, pues, un principio reflexivo fundacional del análisis sociológico del cambio social. 
Si adoptamos una óptica substancialista, asumiremos de manera acrítica los principios del racionalismo ilustrado (que son, en añadidura, parte de los frutos producidos por la modernidad) y el sentido que los mismos dan a la tarea del conocimiento; éste no será entendido en términos de esa capacidad simbólica, representacional y altamente a-racional del ser humano, sino como la capacidad puesta en marcha por las ciencia naturales, puesto que el mundo (sea en su naturaleza social, o psíquica, o biológica, o física, o química...) es la substancia objetiva, dada y preexistente, sobre la que habremos de aplicar esos principios abstractos y formales de la racionalidad de la que somos portadores/as para llegar a su conocimiento en forma de representación. El conocimiento implicaría una tarea en la que distanciamiento y representación formal conforman las operaciones que, supuestamente, amparan la dicotomía sujeto/ objeto, su distinción, neta separación y plena independencia.

Si no adoptamos esa óptica y nos situamos en una perspectiva relacional y reflexivista, asumiremos de manera crítica dichos principios y trataremos de ir más allá de lo que los mismos marcan de antemano como límite a nuestra tarea de conocimiento. Lo primero será poner en suspenso ese distanciamiento de la realidad presupuesto por el objetivismo naturalista como disposición necesaria para alcanzar un conocimiento de dicha realidad: no podemos dejar de estar en y ser partícipes de esa realidad, social, que queremos entender. Y eso implica que el conocimiento sociológico será siempre local, contextual y condicional pues lejos de ser un ámbito abstracto de representaciones es la resultante práctica de la existencia de quienes lo formulan. Como bien dice Bourdieu, la tarea primaria del quehacer sociológico es la de evidenciar las particulares condiciones de posibilidad de quien lo formula, esto es, qué es lo que ha podido propiciar que alguien esté en condiciones de producir conocimiento sociológico sobre el mundo o, al menos, de pretender hacerlo. El primer e ineludible condicionante, insuperable, del conocimiento sociológico es la singularidad insustituible de quien lo produce, alguien que es tan agente social, tan objeto sociológico, como cualquiera de las personas que pueblan ese mundo del que habla.

Y así, cabe entender, en parte, la propuesta que aquí se defiende a partir de la singular condición, como sociólogo, de su autor, y dar sentido a la formalidad que supone este texto a partir del conocimiento de las condiciones de posibilidad, vitales, que lo han podido propiciar. La biografía del/de la autor/a de una obra es parte del sentido de la obra misma, de tal modo que creo que clarificará un tanto la presente propuesta una puesta en perspectiva, reflexiva, biográfica, del proponente.

Es este ejercicio de "autobservación" el que puede evidenciar la coherencia de conjunto que se pretende lograr. Cuando digo autobservación no pretendo dar a entender que de lo que se trata es de un ejercicio de introspección autocrítico; el concepto está bien fundamentado metodológicamente y ha sido ingrediente central de mi tesis doctoral; autobservación supone, metodológicamente, una implicación práctica, como agente social, junto a otros, en una determinada realidad social, siempre procesual, y la subsiguiente y retrospectiva interpretación de dicha experiencia práctica poniendo en suspenso, en la medida de lo posible, esa implicación práctica y vital para tratar de dotar de sentido a dicha experiencia más allá de los sentidos (representaciones) que la misma propiciaba y hacía funcionar para sus 
protagonistas; pero no poniendo en cuestión o negando dichos sentidos, sino incorporándolos como parte del ejercicio autobservacional. La autobservación es la traducción formal, en términos metodológicos, de la reflexividad constitutiva de nuestra existencia social. Procedamos, pues, a ese necesario ejercicio de autobservación.

El autor, de origen social humilde, siempre tuvo un talento excepcional para las cuestiones escolares. Caben posibles explicaciones para ello, que no vienen quizá al caso y remitirían a un marco interpretativo psicoanalítico en el que una figura materna incapaz de proporcionarle reconocimiento afectivo (dado que atribuiría al hijo la culpa del suicidio del padre y, por tanto, sería incapaz de otorgarle dicho reconocimiento) propició una sublimación de lo afectivo en lo intelectual, en búsqueda de ese reconocimiento negado. Dada esa brillante trayectoria, el destino, según los dictámenes al uso y dada la asunción generalizada de que todo el mundo podía acceder a estudios universitarios era que "el niño tiene que estudiar ciencias" (los "listos" eran de ciencias y los "tontos" de letras; al menos, según los sentidos propios del mundo en el que vivía el autor). Dado el expediente académico poseído, el "niño" podía elegir cualquier estudio universitario que quisiera y optó por la ingeniería de moda, informática (realmente, no fue una decisión suya, sino necesariamente lo que tenía que hacer según el parecer de todo el mundo).

Las vicisitudes de la vida, la efervescencia hormonal de esa época postadolescente pre-juvenil, la recientemente adquirida independencia de estudiante sustraído a la supervisión familiar directa y la mala gestión de la facultad elegida, en otra ciudad distinta a la de origen, hicieron que ese primer año académico universitario fuera un fracaso. A ese primero siguió uno segundo igual de improductivo, en otra ingeniería distinta, telecomunicaciones, y en otra ciudad distinta. En su tercer año universitario, el autor se enfrentaba, de nuevo, al proceso de ingreso, y dada su ignorancia, y la fuerte sugestión que suponía el ocio vacacional veraniego, postergó el trámite hasta septiembre y no realizó la preinscripción en junio. Estamos en Madrid, optando a una ingeniería de la Universidad Politécnica, cuyos cupos de acceso quedaban cubiertos siempre en junio. De modo que cuando salieron las listas de admitidos, el autor comprobó con estupor que figuraba en las mismas en una disciplina que había elegido como última opción, la undécima, dada la recomendación de que se rellenasen, en orden de prioridad, esas once casillas por si la primera elección (o la segunda, o la tercera,...) no fuera factible, precisamente, por cuestiones de cupo. La disciplina se llamaba "sociología" y el autor no tenía noción, en ese momento, de que existiera tal disciplina (la había incluido en la selección de manera más bien lúdica y jocosa: "sociología... ¿qué será esto?... bueno, la pongo, que más dá, total es la última casilla y ya he puesto todas las ingenierías...").

Evidentemente, no hubo un principio vocacional en la formación sociológica del autor...

La sociología resultó interesante, mucho menos tediosa y mecánica que las ingenierías; y daba pie a... pensar, cuestionar, discutir. Así que tras dos años perdidos, la sociología fue el medio de reintegración del autor a la excelencia académica (16 matrículas de honor, 10 sobresalientes, 2 notables y 1 aprobado en el expediente de licenciatura). Pero, evidentemente (hoy lo es, entonces, no) 
el fracaso previo con las ingenierías hacía del licenciando en sociología un científico frustrado, de modo que el descubrimiento de una línea de investigación altamente crítica en el ámbito de la sociología de la ciencia (más propiamente, sociología del conocimiento científico, para distanciar dicha corriente de la ortodoxia funcionalista elaborada por Merton) suscitó su atención tempranamente. La estructura de las revoluciones científicas de Thomas Kuhn fue el desencadenante inaugural. Ahí decidió lo que habría de ser su "objeto" de investigación doctoral: el sociólogo-científico-frustrado estaba aplicando, primero de manera inconsciente, luego tomando plena conciencia de ello, un principio de reflexividad, puesto que asumir la Ciencia como objeto de estudio, y desde una perspectiva crítica, era asumirse a sí mismo, en su condición de científico frustrado (pero también con las capacidades escolares adquiridas en el intento), como objeto de estudio.

En esa implicación reflexiva con el análisis sociológico de la ciencia fue cobrando forma concreta todo cuanto había ido asimilando en sus años de formación, en los que, como agente social partícipe de ese proceso vital que es estudiar una carrera universitaria, compartió experiencias, inquietudes, opiniones, discrepancias, discusiones con compañeros/as y profesores/as; y en ese discurrir se fue conformando lo que podemos denominar una "toma de posición" que acabó siendo plasmada documentalmente en una tesis doctoral. La tesis versaba sobre una ecuación física y pretendía dotarla de sentido sociológico a partir de un trabajo de campo que había consistido en estudiar Ciencias Físicas. Es imposible, se dice ahí, comprender en integridad un formalismo matemático de la ciencia a partir de su mero formalismo; es el proceso vital de aprendizaje, y los saberes no formalizables que en él van sedimentando, lo que permite que una ecuación tenga el sentido que tiene para quienes están en condiciones de atribuirle su sentido legítimo.

Para llegar a afirmar esto (que desarrollado con el rigor y el pormenor que exige el trámite de una tesis doctoral, supone 475 páginas) el autor tuvo que tomar conciencia de su posición personal y su plena implicación vital con "La Ciencia" (la "dura") como trayectoria vital frustrada y asumir que su capacidad de dar sentido al trabajo de investigación en el que se había involucrado era fruto, casi cabría decir, necesario, de su particular posición, como ser humano, en el mundo. Esto fue elaborado formalmente a partir de la asunción de la condición constitutivamente reflexiva de las prácticas sociales (revisando y criticando la ortodoxia reflexiva que se ha instalado desde hace tiempo en el pensamiento sociológico: la reflexividad como condición ineludible del existir, práctico, humano y, por ende, de las dinámicas del mismo en su condición de agente social, y no la reflexividad como plus de excelencia portado metodológicamente por el investigador social frente a la carencia del mismo por parte de los "ingenuos" seres humanos de los que habla), entre ellas, las científicas y, por lo tanto, las del científico social investigador de las prácticas científicas. Sobre esa premisa, la metodología autobservacional, la capacidad, infundamentable desde premisas objetivistas, naturalistas, substancialistas y racionalistas, de situarse en la condición dual de partícipe y observador, simultáneamente, sujeto y objeto de conocimiento, vino a ser un correlato necesario.

Con estos ingredientes el edificio quedaba más o menos conforme, y, sin embargo, el autor tenía la necesidad de un agregado; necesidad, nuevamente, 
derivada de su particular condición reflexiva de agente social implicado en la práctica social de estudiar una licenciatura de sociología. Porque en ese trance vital había estado la figura, como profesor, de Jesús Ibáñez; figura que había marcado decisivamente los intereses e inquietudes intelectuales del autor y que, además, había propuesto un concepto altamente heterodoxo (tan heterodoxo que no se formulaba en positivo, sino en oposición a los dos términos fundamentales de la lógica argumental y procedimental positivista, los de deducción e inducción). El tal concepto venía a indicar, lisa y llanamente, que la capacidad de conocimiento humano está más allá de los formalismos "ductivos", más allá, o sea "trans": conocemos por transducción (gustaba mucho Ibáñez de ir al fondo del sentido de los conceptos apelando a la etimología; haciendo explícito lo que por implícito del vocabulario que utilizamos hace que no seamos realmente conscientes de lo que estamos diciendo cuando hablamos ${ }^{6}$.

Con gran pesar de mucha gente y, en particular, de mi director de tesis, Ramón Ramos (para quienes Ibáñez, ya muerto, era ininteligible, rancio estructuralista -esto no lo dijo Ramón- y poco operativo para el quehacer de la investigación sociológica), el autor se empeñó en incorporar esa noción, mero esbozo conceptual, en el aparato teórico-metodológico de su tesis. Siendo gallego y, por ello, testarudo, llevó a buen puerto el empeño (eso sí, muy rebajado en su elaboración final respecto de lo que habían sido las intenciones iniciales).

Aquí surgió un descubrimiento fundamental. Ramón, finalmente asumida la irreductible intención del autor de incorporar la transducción en el aparato formal de su tesis, sugirió la lectura de la interpretación que Paul Aubenque había hecho de la phronesis (prudencia) aristotélica. Efectivamente, en esa lectura, la inclasificable virtud (que no plenamente tal según los cánones sofísticos) de la prudencia remitía a una aptitud humana, práctica, infromalizable, en la que un ser humano indefenso se enfrentaba a la urgencia vital de sobrevivir, actuar, con conocimientos precarios para ello (frente a la omnipotencia de la sophia incuestionable de los dioses del Olimpo), en un mundo incierto. Ser prudente, obviamente, era ser transductivo.

\footnotetext{
${ }^{6}$ Una de las muchas categorizaciones "tricotómicas" que acostumbraba a formular lbáñez (como la de inducción/ deducción/ transducción) que dejó "huella" en la trayectoria del autor era la de la posición conversa, subversa o perversa en la que necesariamente ha de estar situado el investigador social. El investigador converso acata las ortodoxias, se las cree, y las hace funcionar (siempre en beneficio del poder instituido que lo controla, sea él o ella consciente o no de dicho poder); el investigador subverso se declara abiertamente contrario a las ortodoxias y se enfrenta a ellas (se da cuenta de la existencia de ese poder y lo rechaza, pero al hacerlo, reconoce fácticamente su existencia $\mathrm{y}$, sin darse cuenta, la disputa, fruto de ese reconocimiento, queda sujeta a las reglas prestablecidas por el mismo); el investigador perverso, per-verso, rodea las ortodoxias y las fuentes de poder, hace como que no se entera pero desde luego dista mucho de confraternizar; en palabras de Ibáñez, va hasta los fundamentos de la ley (el dictado impositivo del poder) para llevarla hasta sus últimas consecuencias y, con ello, desvelar su arbitrariedad. El perverso, como el transductivo, tiene como intención estar un paso más allá de lo evidente, desvelar lo que, innombrado, eludido, es fundamento arbitrario, o sea, potestad exclusiva de quien manda (por las razones que sea). Ser perverso, pues, más allá de las connotaciones convencionales adheridas al término, en términos de la investigación sociológica, y, claro está, desde cierta perspectiva, es una virtud a perseguir (y que no se alcanza fácilmente).
} 
Bien. Pues esto es sólo la primera parte del relato, reflexivo y autobservacional, que conduce a la fundamentación teórico-metodológica de un proyecto docente que versa sobre el cambio social y uno investigador que lo hace sobre discapacidad.

La segunda parte surge de este ejercicio biográfico-autobservacional y se anticipa aquí para ser desarrollada conceptualmente en el siguiente epígrafe. El autor, aún inmerso en el proceso vital de elaboración de su tesis doctoral, fruto de un accidente, adquirió la condición de persona con discapacidad. Ello supuso una ruptura en su vida, correlativa de otra en su trayectoria académica; fue partícipe, también inconsciente en esos momentos, de todos los condicionantes estructurales que conforman la existencia subordinada, oprimida, marginada, excluída de las personas con discapacidad. Adquirió una minus-valía, es decir, la condición vital de ser menos válido que el común de sus congéneres; y la adquirió, no porque la tuviera, sino porque, teniéndola o no, se creyó que de hecho la tenía porque eso era lo que el entorno, el afectivo inmediato y el profesional mediato, decían.

Tras el trance, el consiguiente y largo período de convalecencia y rehabilitación, la asunción de esa condición minus-válida impuesta y el período de profunda depresión asociado, el autor se reintegró a las tareas académicas.

Es interesante detenerse, analíticamente, en este momento; momento en el cual la investigación doctoral, sobre la ciencia, está todavía en curso, y se da la ruptura vital que supone adquirir una discapacidad. Dada la lógica imperante en relación con las personas con discapacidad, recuperar un proyecto de vida truncado sólo es posible, para la mayoría de ellas, y el autor formaba entonces parte de esa mayoría, obviando el hecho de la discapacidad y haciendo como si la misma no existiese (de lo contrario, esa condición minus-validante que los entornos de convivencia hacen recaer sobre las personas con discapacidad, de hecho, in-capacita). Y así se cursó la culminación de la investigación doctoral: el sociólogo de la ciencia lo era y lo de-mostró con independencia de que en el momento de la de-mostración fuera una persona con discapacidad (dato mencionado, marginal y periféricamente en el acto de la defensa, haciendo expreso que esa condición del doctorando había sido puesta en suspenso, elidida).

En ese trance, igual que Kuhn fuera un desencadenante para los intereses en relación a la sociología de ciencia, apareció otro texto (un regalo de una persona muy cercana afectivamente y que había sido parte interesada en la edición del mismo, financiada por una importante Fundación de una gran empresa española), una traducción de una compilación de artículos de autores ingleses y estadounidenses de Len Barton que llevaba por título Discapacidad y sociedad. De su lectura surgieron importantes consecuencias. Primera; había una línea de investigación, crítica, en sociología, que tenía reconocimiento y cuyo objeto (y sujeto) de estudio era la discapacidad. Segunda; en España, en los circuitos académicos, no había noticia de ello. Y tercero; reflexiva, transductiva y autobvservacionalmente no podía eludir el hecho de que, dada mi condición personal y mis compromiso críticos intelectuales, si eso era así, yo tenía que formar parte.

Si como científico "duro" frustrado hube de elaborar una tesis doctoral sobre sociología de la ciencia, como persona con discapacidad no tenía más opción, 
humana, reflexiva y autobvservacional, que dedicarme, en adelante, a la sociología de la discapacidad, y hacerlo, claro está de manera transductiva.

$\mathrm{Y}$ así fue. $\mathrm{Y}$ por eso en el programa docente figura un último tema sobre cambio social dedicado a la discapacidad y por eso el proyecto de investigación remite, dada mi actividad investigadora actual, a la discapacidad.

Pero aún estamos muy lejos de justificar que ello marque una sólida continuidad con lo antedicho. Vamos a tratar de enmendar la falla...

\section{Paso preliminar 2: cuerpo y emociones frente a racionalidad}

Siguiendo con el relato biográfico-autobservacional, como parte necesaria de la fundamentación académica de un proyecto docente y un proyecto de investigación, una vez descubierto que existe un ámbito, con reconocimiento y trayectoria institucional, además crítico, para el estudio sociológico de la discapacidad, se suscitan nuevas aperturas teóricas, fruto, como parte de la trayectoria vital del autor, de los contactos personales que se generan a partir de esta nueva opción de investigación. Contactos que provienen fundamentalmente de América Latina, y más específicamente de Argentina ${ }^{7}$, algo que, entre otras cosas (lo cual es muy relevante tanto para la comprensión sociológica del cambio social como de la discapacidad), hace que uno tome conciencia de sus sesgos occido- y euro-céntricos.

El primer descubrimiento, o más adecuadamente, re-descubrimiento, es la noción de habitus de Bourdieu. El habitus ya formaba parte de los "ingredientes" reflexivos de la tesis doctoral; pero era fruto de una lectura insuficiente y parcial del autor. La condición ambivalente, estructurante y estructurada, de esa habilidad práctica para desenvolverse competentemente de los agentes sociales en cuantos contextos sociales sea necesario que actúen se ajustaba, dada su carga crítica de fondo, a la noción de reflexividad constitutiva de la acción social que surgía de las propuestas de Garfinkel (con el añadido de que Steve Woolgar había formulado, a su vez, una reflexividad bastante análoga aplicada al estudio específico de las prácticas científicas).

Añadida a su condición de científico frustrado, propiciatoria de una investigación en el ámbito de sociología de la ciencia, la condición de persona con discapacidad, y bajo el condicionante del aparato conceptual desplegado por esa condición previa (reflexividad, autobservación, transductividad), emergía una nueva comprensión (un nuevo sentido incorporado a la práctica vital del quehacer sociológico) respecto del habitus bourdieuano. Y ese nuevo sentido suponía, para la singular posición vital de "observador" del autor, un paso más allá del paso más allá dado previamente.

Desde esa perspectiva crítica sobre la discapacidad descubierta a raíz de la compilación de Len Barton, el denominado modelo social, de lo que se trata es de darle la vuelta a la tortilla cocinada por la ciencia médica. La ortodoxia

\footnotetext{
${ }^{7}$ Y más en concreto, porque dada la ocasión y el planteamiento en el que me sitúo, creo que debe ser mencionada, Carolina Ferrante, becaria doctoral del CONICET argentino, cuya tesis doctoral, un estudio sobre el significado y las implicaciones de las prácticas deportivas para las personas con discapacidad motriz, está a punto de ver la luz; su colaboración y aportación ha sido un "factor" determinante.
} 
canonizada por la modernidad en relación al sentido y prácticas sobre la discapacidad estipula que la misma consiste en un atributo de la persona derivado de un déficit fisiológico; esto es, una causalidad corporal determina un fenómeno de naturaleza individual. Si le damos la vuelta a la tortilla de la discapacidad, resulta que el determinante fundamental que condiciona la existencia de quienes poseen una (o varias, cual es el caso de quien escribe) no es tanto el substrato fisiológico como los condicionantes estructurales (materiales y simbólicos) del mundo (social) en el que han de desenvolverse; el dis- de la discapacidad no proviene de la merma fisiológica, sino de todas las barreras, obstáculos, impedimentos, que generan unas estructuras sociales edificadas sin tomar en consideración sus necesidades. Son los contextos de convivencia los que dis-capacitan y, como consecuencia, generan procesos de marginación y de exclusión social. La discapacidad es un fenómeno social y su condición determinante, según estos autores, con Mike Oliver a la cabeza, es la opresión.

Para superar ese efecto de conjunto que es la opresión ejercida sobre la gran mayoría de personas con discapacidad, en el ámbito académico, el punto de partida es dar voz a esas personas, partir de sus experiencias, para determinar y delimitar cuál es la verdadera naturaleza, social, de la discapacidad. Las personas con discapacidad han de tener parte activa en la investigación sociológica de la discapacidad, han de aportar su experiencia y su conocimiento, han de estar en condiciones de tomar decisiones en el discurrir de dicha investigación; han de ser sujetos/objetos de la misma; y han de poder apropiarse de los resultados de dicha investigación para utilizaros como herramientas para la supresión de esa opresión que sobre ellas recae. A esta pretensión los autores del modelo social la denominan "investigación emancipatoria".

Y resulta que una amplia mayoría de dichos autores son, además, personas con discapacidad. Del planteamiento, y de la condición de esos investigadores, parte constitutiva de lo que investigan, la discapacidad, deviene una evidente continuidad teórico-metodológica con el marco reflexivo y autobservacional que sustentaba el trabajo de la tesis doctoral.

Sin embargo, la tarea de trazar de manera expresa dicha continuidad está aún por realizar. De hecho, el presente texto es una primera tentativa. La tarea, además, requerirá bastantes refinamientos adicionales, puesto que por el camino de la investigación realizada hasta la fecha han surgido elementos adicionales a incorporar. Como anticipábamos, alguno de ellos tiene que ver con la noción de habitus de Bourdieu.

Bajo la lógica de la investigación emancipatoria, y a falta de financiación para desarrollar trabajos de investigación empíricos, la fuente de datos fundamental, dado que hay que partir de la experiencia de las personas con discapacidad, ha sido la experiencia propia (evidentemente, nada más autobservacional) y un intento por situarla en una perspectiva que pueda extraer de la misma afirmaciones consistentes generalizables: ¿cómo se configura esa experiencia? Retomando a Bourdieu, fundamentalmente a partir de la lectura de Meditaciones pascalianas, parece más que evidente que dicha experiencia viene marcada por la inculcación de un habitus muy específico, de tal modo 
que es pertinente hablar de la existencia de un campo social de la discapacidad ${ }^{8}$.

Dado el monopolio de la ciencia médica, dicho campo y el habitus que incorpora en los agentes que se comprometen en él, versará sobre la salud; el conjunto de disposiciones que permitirán dotar de eficiencia a los agentes en dicho campo (sin conciencia expresa de ello, imbuidos de conocimiento práctico) vendrá provisto por dictámenes médicos en torno a la salud. De aquí emerge la determinación del capital específico en disputa en dicho campo: ¿por qué merece la pena jugar el juego que propone la ortodoxia médica de la rehabilitación? Porque, aún siendo imposible una curación completa ${ }^{9}$, merece la pena lograr el máximo acercamiento posible a la misma, pues de ello se derivará un reconocimiento social, avalado por la ciencia médica, mayor (es infinitamente mejor que, sea cual sea el tipo de discapacidad, la catalogación clínica sea de grado "moderada" o "leve" que de "severo"). Estamos pues ante un capital simbólico, anudado en torno a la promesa incumplible de la curación.

De esto puedo dar fe, insisto, a partir de la experiencia personal. ¿Cuál es la primera pregunta que se desencadena - acuciantemente pronunciada por el entorno familiar inmediato- una vez constatada la discapacidad... una de ellas? La pregunta es: "¿y esto tiene cura?". La respuesta obtenida (y han sido varios/as los/as expertos/as clínicos/as que la han respondido) no ha sido la que pudiera, quizá, esperarse: "no". Siempre ha sido: "por el momento, no, pero los avances en medicina son tan espectaculares que puede ser que en unos años sea posible...". Ahhh... que me voy a poder curar, que me lo dice la ciencia médica, mediante una promesa permanentemente incumplida pero, como diría Bourdieu, que precisamente cobra toda su eficacia por el incumplimiento, porque está apelando a mi deseo, no a mi conocimiento. Ése es el capital simbólico que hace implicarse a todas las personas con discapacidad en el campo social en el que están inmersas y del que derivan todas las disposiciones prácticas que constituyen el habitus que se les inculca.

Llegados a este punto es cuando el habitus (leído, interpretado y vivido ahora desde la experiencia personal de la discapacidad) cobra una nueva textura. En principio, en la andadura de los estudios sobre la ciencia, era un bonito concepto heterodoxo que encajaba con el planteamiento crítico que se trataba de proponer, rompía con las dicotomías epistemológicas al uso y permitía desracionalizar el conocimiento científico aportándole un ingrediente práctico, vital

\footnotetext{
${ }^{8}$ A efectos de evitar malentendidos, y según se deriva de las propias afirmaciones de Bourdieu, un tal campo social, el de la discapacidad, propiamente hablando no existe; se trata de una etiqueta, de una catalogación genérica que permitirá enfocar la investigación en contextos geográficos y temporales específicos. Digámoslo así: en torno a la discapacidad se constituye la dinámica propia de un campo social (hay una estructura relacional de posiciones determinadas por el volumen de determinado tipo de capital específico que poseen, y por el que disputan, los agentes sociales en dicho campo —en seguida se considerará dicho capital), cuya comprensión, además, dependerá de la determinación de la historia de su constitución, pues es la historia de un campo social la que determina su configuración en un momento dado, de tal modo que podríamos hablar, en tanto que un campo social efectivamente existente, del campo social de la discapacidad en la España de inicios del s. XXI

9 Una de las consecuencias inmediatas de la apropiación por parte de la ciencia médica del tratamiento de la discapacidad es su asignación como enfermedad; enfermedad, paradójicamente, incurable, pero que determina la misma actuación que dicha ciencia aplica ante cualquier enfermedad: la curación.
} 
y no formalizable. Pero se quedaba en un concepto, algo abstracto, extraído de la lectura, y que encajaba bien con el conjunto de abstracciones que se estaban manejando.

Ahora, el habitus, reflexiva y autobservacionalmente, es una experiencia vivida. Todos los procesos de in-corporación (en el sentido literal de su sedimentación en el cuerpo) del mismo se han dado: el diagnóstico clínico, el tratamiento, la rehabilitación, el seguimiento médico, la asistencia psicológica, el asistencialismo de los aparatos estatales, la creencia ciega de la familia... todo lo constata. En primera instancia. En segunda, hace emerger al gran olvidado de las ciencias sociales que, precisamente por serlo, es el gran protagonista de las operaciones de intervención de los poderes a los que estamos sometidos/as: el cuerpo.

¿Sobre qué versan las prescripciones y proscripciones médicas en el campo de la discapacidad? Sobre el cuerpo ¿En dónde radica la eficiencia que provee el habitus para cualquier persona/ agente social? En el cuerpo. Somos cuerpos socializados, desde la cuna, mucho más que sujetos racionales, abstractos, portadores de conocimiento formalizable. Nacemos y ya hay un vestuario predispuesto en función del sexo para nosotros (rosa o azul como marcas cromáticas de distinción); a ellas, los agujeros en las orejas y el pelo largo; ellos, sin agujeros y corto; pantalones, faldas; en el colegio empieza un largo adoctrinamiento corporal marcado por las dicotomías sentado/ en pie, silente/ hablante, escritural/ oratorio, etc., en la que los cuerpos ejercitan hasta la extenuación sus prácticas acordes a tales disciplinamientos. Una vez transmutado el habitus de concepto acoplable a un esquema analítico, formal, en palpable y vívida experiencia, la óptica de conjunto se reformula. Es en ese momento, por ejemplo, cuando el Foucault de la anatomopolítica y de los disciplinamientos cobra verdadera entidad.

Vivimos en un mundo hiper-tecnologizado-cientificizado (la expresión "está científicamente comprobado", como constructo retórico arbitrario, como caja negra, sirve tanto para impulsar una política de criminalización de los/as fumadores/as como para vender un detergente) pero en el que, todavía, son nuestros cuerpos los depositarios de nuestra condición humana; son ellos los que nos hacen eficientes para vivir en sociedad (la vertiente positiva) y los que nos sujetan a todas las lógicas de sometimiento que permiten que las convenciones sigan su curso sin mayor sobresalto. Los actos más intolerables para los poderes fácticos son aquellos en los que los cuerpos se expresan sin atención a las normas (tomar colectivamente una capilla universitaria enseñando las tetas es "terrible", porque las mujeres, cuerpos, además de alma tienen tetas... pero eso debe ser omitido...; acampar en la Puerta del Sol, más allá de todos los revestimientos interpretativos que lleve aparejado, supone unos cuerpos desagradables para el servicio público haciendo sus cosas dónde no deben: ¿qué hacen todos estos cuerpos aquí reunidos indebidamente, durmiendo, comiendo, debatiendo... quiero esos cuerpos fuera de la "civilidad" que tan arduamente hemos construido...).

Y es entonces cuando los principios, abstractos, formales... por tanto, aún marcadamente racionalistas, de la reflexividad, la autobservación y la transdutiidad cobran su verdadera y humana condición: son aptitudes y disposiciones corporales, son de un orden de realidad que no pasa por la 
argumentación formal. He ahí la creatividad humana, derivada de lo precario de nuestra condición (somos animales, cuerpos en constante peligro de perecer... la muerte, sí, como primera y única certeza de la que disponemos lo es de nuestro cuerpo; vivir es disponer de un cuerpo; morir, dejar de disponer de él) y de la constante incertidumbre que caracteriza el mundo que habitamos. Precariedad constitutiva e incertidumbre medioambiental generalizada son los factores que propician, alientan y modelan nuestra irredenta condición creativa, eso que nos permite estar "más allá", trans-, de los cauces del rigor formal de naturaleza "ductiva".

Evidentemente, esto es de crucial importancia para las personas con discapacidad, para el cambio social en un sentido genérico, y para el que, específicamente, protagonizan. No son sujetos de conocimiento necesitados de "re-programación", son cuerpos necesitados de "rectificación", pues si no, no serán factibles como espacio para la intervención de los poderes que someten al conjunto de los cuerpos que conforman las colectividades humanas: por muy "excedente" en volumen y "carente" en estética que sea mi vecina del quinto (mi edificio sólo llega hasta el cuarto... no se trata de ofender a nadie), siempre será factible hacerle creer que la dieta y la cirugía estética pueden hacerla ser Cameron Díaz; a mis amigos/as que van en silla de ruedas... ¿qué se les puede vender?

Quien escribe no está libre de culpa. Con y sin discapacidad ha sido objeto de todas esas intervenciones... desde siempre. Ahora, en estas líneas, trata de hacer un ejercicio reflexivo y autobservacional. Sin discapacidad: siempre practicó deporte (fútbol, balonmano, ciclismo); primero, porque el "cole" lo proveía y era una buena manera de paliar el tedio propiamente escolar; luego, ya plenamente interiorizadas todas esas sedimentaciones prácticas y discursivas sobre el cuerpo, porque "vendía más" un cuerpo atlético que uno no atlético. Pasamos a un período de inactividad (la "travesía del desierto" que supuso la impregnación universitaria de los principios universalistas del conocimiento según nuestra tradición cultural: no hay cuerpo). Con discapacidad: se recupera el deporte, en este caso con la natación (pero con la más que punible condición de fumador y adepto a la cerveza penitentemente adquirida en la travesía del desierto); se recupera la condición corporalmente más valorada (estética y funcionalmente) del "deportista". Y llega una segunda travesía del desierto: matrimonio, hijos, obligaciones y la imperdonable, según el parecer de la pareja de turno (le pido disculpas por decir esto: ella no lo hacía de mala fe... pero lo hizo), dedicación corporal frente a tanta obligación no era admisible. Y a fecha actual: de la etapa "sin", recuperación del ciclismo, de la etapa "con", recuperación de la natación. Y una sensación, corporal, de creciente regeneración. Pero sujeta a la misma e inmutable lógica: "vale más" (reitero: estética y funcionalmente)... somos cuerpo, lo queramos reconocer o no, y esa nuestra corporalidad, a la par que fundamento de nuestra condición humana, es el ámbito de intervenciones que nos encadena a las lógicas que nos dominan.

Y además, y lo sitúo en párrafo al margen para darle significación, la condición de fumador y bebedor sigue plenamente activa y, siendo complementaria con la de "deportista", que sea de imposible asimilación por la mayoría de la gente dicha conjugación es evidencia de los sometimientos que nos atrapan, anudados en nuestros cuerpos de manera tácita, no expresa, omitidas sus 
verdaderas razones en las argumentaciones que les dan soporte. Porque esto viene al caso, indudablemente, de la presente fundamentación. Y para ilustrar el asunto, quiero exponer dos experiencias concretas, que desvelan tanto lo arbitrario de dichos sometimientos como la extrema estupidez que llegan a provocar, anulando, al conformar nuestra corporalidad, nuestras auténticas capacidades de pensamiento (de pensamiento autónomo, de libertad intelectual).

Al poco de entrar en vigor la segunda fase de la famosa ley antitabaco (esto es, de haberse dado un paso más para la criminalización de los/as fumadores/as y su discriminación y exclusión de los espacios de convivencia) llevé a mi hija, de seis años, a uno de esos parques públicos acondicionados por los poderes municipales que tanto han venido proliferando ${ }^{10}$. Un espacio público, pero al aire libre. Dado el radicalismo ideológico (también en ello tiene la parte principal la ciencia médica y sus alegatos en pro de la salud, pública y privada) que acompañaba a la nueva normativa, intimidado, claro está, por esa incrementada perversidad, deterioro moral y depravada condición humana que, según la ley, me caracterizarían por ser fumador y no querer dejar de serlo, tuve cuidado de observar la señalización del espacio: no había ninguna indicación de "prohibido fumar". Aquí me tranquilicé, puesto que, según la normativa, todo espacio público sujeto a su reglamentación debía indicarlo claramente, bajo pena de sanción al propietario del mismo si no era así; bien, si incumplo la ley, le pongo una denuncia al ayuntamiento por no advertírmelo con el consiguiente cartel, me dije. Así que mientras mi hija, Alma, jugaba, me senté en un banco y encendí un cigarrillo. Al poco tiempo se fue gestando una especie de "movilización colectiva" entre algunas madres y un abuelo que me tenían por objeto de atención; cuando me di cuenta, el tal abuelo se acercó para decirme:

- aquí no se puede fumar

- ¿y dónde lo dice? —respondí.

- hay una nueva ley, ¿es que usted no se ha enterado? Y ya no se puede fumar aquí —replicó el venerable anciano.

- Sí, sé lo de la ley, pero no me consta que prohíba fumar en este sitio; si usted me dice exactamente el apartado de la ley en el que consta eso, yo no fumo aquí. Como no lo sé y no hay ninguna indicación, hasta que no me informen adecuadamente... fumo.

- ¡Voy a llamar a un guardia!

- ¡Perfecto! Hágalo, seguro que él me puede informar debidamente; y si me prueba que la prohibición existe, o sea, dónde lo dice, yo dejo de fumar

\footnotetext{
${ }^{10}$ No puedo dejar de hacer el comentario: menos mal que son niños/as y su versatilidad para el juego está más allá de la estupidez de quienes piensan qué ha de contener un espacio de juego para niños/as; la media docena de artilugios que combinan (en el mejor de los casos; en el peor, un columpio y un tobogán) conducirían al tedio a los diez minutos; la ventaja es que se juntan, ahí y al margen de los artilugios, muchos/as niños/as y de esa su versatilidad colectiva hacen uso para inventarse juegos y sortear la estrechez de miras de la programación estandarizada de los municipios... los/as niños/as siempre lograrán, cuando se junten, divertirse aunque estemos empeñados en querer que sean adultos de pocos años...
} 
- Es usted un... (diversos calificativos desagradables) i¿es que no ve que aquí hay niños?!

- Sí, claro, si yo vengo para traer a mi hija... no vengo sólo a fumar para fastidiarle a usted...

El venerable anciano hizo ademán de buscar algún policía municipal, que no había; el tumulto colectivo de madres que amparaban a su portavoz se desató en comentarios diversos (más calificativos desagradables); mi hija dejó de jugar y se puso a inspeccionar el recinto para, al rato, venir a decirme: "papi, tienes razón, no hay ningún cartel" (se la veía bastante... preocupada). Y finalmente yo acabé mi cigarrillo y el incidente no tuvo más repercusión. Bueno... sí...

Dado el incidente, las sucesivas veces que fui con mi hija al tal parque no entré y me quedaba por la parte exterior de la valla que lo delimita fumando; es decir, aproximadamente a medio metro de distancia del lugar en el que estaba cuando se desató la indignación colectiva. Y comprobé que era la práctica que se había adoptado por parte de todo el mundo.

Pero, sobre todo, hay que señalar que el parque está situado en una calle de importante afluencia de tráfico, cuya circulación emite una considerable cantidad de gases perniciosos para la salud... pero, con la nueva ley... ¡no han cortado el tráfico en la calle! ¿y los niños, es que no han pensado en ellos...?

Vamos con la segunda "escena cotidiana" (y luego retomamos el hilo argumental). También está Alma como partícipe (debe ser que, de un modo u otro, quiero hacerla parte y protagonista del acto que suscita este texto...).

Decidí introducir a mi hija, una vez retomada la afición ciclista, a la bici. Hacía poco que había aprendido a andar en ella sin necesidad de ruedines y consideré que era una buena ocasión compartir con ella esa actividad y así facilitar que fuera perdiendo las inseguridades. Le compré una bici y estuvimos saliendo varios días seguidos (a los tres, el cambio, en su soltura, era notable: habitus); viendo la evolución le propuse irnos a la Casa de Campo en bici de excursión: salir de casa con las bicis hasta el tren de cercanías para llegar hasta la estación de Príncipe Pío, al lado de la Casa de Campo, y luego dar unas vueltas por allí. Nos fuimos (Alma estaba encantada con su nueva bici y con la actividad que la misma implicaba). A la hora de comer, nos sentamos al borde del lago, en un banco, con las bicis apoyadas junto a nosotros. Yo me llevé, para acompañar los sandwiches, una lata de cerveza. El "evento dos" se suscita en el momento en el que, acabada la comida, yo estoy con la lata de cerveza y he encendido el protocolario cigarrillo post-ingesta. Una niña, un adulto, dos bicis, una cerveza y un cigarrillo: una pareja que paseaba por el sendero que linda el lago de la Casa de Campo pasa a nuestro lado, y oigo, cuando ya nos han sobrepasado, un comentario por parte de él, más o menos de este tenor: "¿te has fijado, ése, con la hija y las bicis, fumando y bebiendo...? para coger energía... habráse visto... luego dirá que viene a la Casa de Campo, con su hija, a hacer deporte, cuando nadie le ve".

Cambio social, discapacidad, cuerpo y emociones (con el anticipo de la reflexividad-autobservación-transductividad). Evento 1: entra en vigor una ley, antitabaco, que versa sobre la salud pública, con el aval de la ciencia médica para su adecuada justificación; están los niños, que son una de las partes más vulnerables de la especie humana; está el aparato ideológico del Estado, los 
mensajes mediáticos en torno al cuerpo, y el ideologema de salud como estandarte de compra-venta. Bueno, es obvio ("está científicamente comprobado") que fumar perjudica a la salud. Luego es malo; luego es malo en absoluto; luego requiere medidas. La salud, pública, objeto de intervención de los poderes estatales está en riesgo por culpa de los/as fumadores/as: erradiquemos esa perniciosa práctica. Bien, ¿dónde están las órdenes de clausura de las empresas tabaqueras? (manejan mucha pasta, parte de la cual va a los poderes públicos; amén de que, en ciertos estratos sociales, el gerente sectorial de Reynolds Tobacco es compañero (masculino, siempre) de estudios del Director General de turno, comparten aficiones y cenas (regularmente) con sus familias; probablemente, comparten información sobre las tendencias de la bolsa). Hombre, seamos razonables: busquemos al culpable (que no tiene interese compartidos con quién asigna la culpa, si no, no vale) y vayamos a por él. El/la fumador/a, que como sujeto racional de conocimiento, un día, indebidamente, tras un cálculo racional de eficiencia y rendimiento, decidió fumar porque le resultaba más rentable. Basta con cuestionar ese cálculo (algo que, entiendo, se creen los/as promulgadores/as de la legislación). Digámosle que ya no resulta rentable; obviemos que detrás de cada fumador/a hay una biografía, unas razones subjetivas, unas elecciones, unos deseos, unos sentimientos... digamos que fumar, al margen de todo eso, es un acto que, según la ciencia médica, "puede matar". Listo: a ver quién puede decir que no (por cierto, nos olvidamos del "hombre Marlboro", aquel que cabalgaba en el ocaso de un idílico Oeste estadounidense, blandiendo un lazo de apresar reses y que, todos sospechábamos, tenía en su cabaña a una espectacular mujer aguardando para "compensarle" por su ardua labor cotidiana de cowboy... que si no fumara Marlboro, no tendría nada de eso...).

Así que, advenida la ley, se abre la veda para el fundamentalismo popular: si estás, por medio metro, inflingiendo la directriz, eres Satanás, pues tu culpa es la de contaminar niños; salvado el medio metro (con efectos absolutamente análogos en cuanto a lo que estás haciendo, dado que el humo se desplaza según sople el aire, con independencia de las vallas), eres una persona respetable y digna de consideración, como todos/as los/as conductores/as que gasean regularmente este parque de niños y no son, por hacerlo, objeto de intervención política (y sumamos a las tabacaleras dos sectores estratégicos para las finanzas públicas: el del automóvil y el de las empresas energéticas petróleo, vamos-). Y ahí tenemos a un abuelo indignado con el fumador e ignorante de los tubos de escape; pero fundamentalista, claro está, porque está bajo el amparo de la "ley" (que él ignora, profundamente, en su naturaleza propiamente legar, jurídica, e ideológica, pero que le sirve de incontestable baluarte para desatar su furia contenida -ésa que llevamos todos/as dentro y que nos reprimen sistemáticamente).

Y bueno, aquello de que "ahora que no lo ven" (fuma y bebe cuando luego dirá que hace deporte, con su hija que, pobrecita, dirá que "fui con papá a la casa de campo con las bicis", pero jamás que "papá se tomó una cerveza y fumó un cigarrillo cuando comíamos" porque es obvio que la someteré a torturas terribles si lo hace, pues fumo y bebo y nada mejor se puede esperar de mí...).

En ambos casos, el referente central, aunque obviado y eludido, es el de un cuerpo no conforme con las directrices médicas de la salud, mediadas por las operaciones de intervención política. Cuerpo fumador, cuerpo contaminante de 
la pureza infantil; que no se atiene, por lo tanto "desviado", a las puniciones supuestas (y no conocidas de hecho) al respecto; portador de un defecto moral; cuerpo hipócrita y mentiroso que usará a esa infancia (cuando no lo ven) para que diga que es lo que no es. Y todo esto, sin que la retórica y las actitudes que la misma desencadena tengan siquiera atisbos de que va de eso, del cuerpo.

Para una consideración realmente seria de la "realidad social", en consecuencia, del cambio que constitutivamente la define, hemos de detenernos para recuperar la corporalidad que, integralmente, nos define y conforma, nos sujeta a límites insoslayables (todos/as vamos a morir algún día) $\mathrm{y}$, al mismo tiempo, nos permite desanudarnos, si nos dejan, de cuantas constricciones recaen sobre nosotos/as (si puedo escribir esto es porque tengo unas manos que teclean en un teclado de un ordenador; sin esas manos -en mi caso, pues otras personas con discapacidad pueden "teclear" sin usar las manos; en todo caso, necesitan una parte anatómica que lo haga-, ¿existirían estas líneas?).

El "prejuicio" racionalista que informa la cultura de la que somos herederos/as ha hecho que nos olvidemos del cuerpo, que lo pongamos en suspenso, que no consideremos que es parte fundamental y definitoria de quienes somos. Paralelamente, puesto que hay mecanismos que operan sobre él para conformar nuestra existencia a las modalidades más acordes con quienes más se benefician de ella, la "industria" sobre el cuerpo es cada vez más potente.

En definitiva: estamos ante una de las principales hipocresías de la modernidad. El sujeto moderno no tiene cuerpo porque es eminentemente racional (es el espacio del discurso ortodoxo), mientras que el ser humano moderno es un ámbito de existencia real objeto de intervención masiva por todos los poderes que tratan de sustentar la vigencia, pertinencia y bondad de ese discurso en torno a ese ficticio sujeto (que, de existir, radica corporalmente en despachos profesionales bien, muy bien, acomodaos).

Y ya sucintamente, para cerrar este más allá del más allá, sólo un breve comentario (se nos ha quedado por el camino lo de las emociones, y aún cuando, desde mi modesto entender, viene dado de manera implícita en lo antedicho, conviene "ponerlo en limpio").

Digamos que nos parece factible la formulación de Bourdieu sobre el habitus y los campos sociales y los diversos capitales vinculados. Bueno, ¿y de dónde viene todo eso, qué podemos encontrar, genéticamente, que lo haga plausible? Me remito a un párrafo de sus Meditaciones pascalianas (y será la única referencia bibliográfica expresa que aquí se incluya) que me parece determinante como punto de partida:

«La forma original de la illusio es la inversión en el espacio doméstico, sede de un complejo proceso de socialización de lo sexual y de sexualización de lo social (...) un campo de relaciones sociales, constituido así en objeto de interés y de preocupación, en el que el niño se encuentra cada vez más implicado y que constituye el paradigma, así como el principio, de la inversión en el juego social. ¿Cómo se efectúa el paso, que describe Freud, de una organización narcisista de la líbido, en la que el niño se toma a sí mismo (o a su cuerpo) como 
objeto de deseo, a otro estado en el que se orienta hacia otra persona y entra de este modo en el mundo de las "relaciones de objeto" (...)?

» (...) la labor pedagógica, en su forma más elemental, se basa en uno de los motores que figuran en el origen de todas las inversiones ulteriores: la búsqueda del reconocimiento (...) el niño sólo podrá describir a los demás como tales a condición de describirse a sí mismo como "sujeto" para el que existen "objetos" que tienen la particularidad, a su vez, de considerarlo como "objeto" (...) su ser es un "ser percibido", un ser condenado a ser definido en su verdad por la percepción de los demás.

»Ésta podría ser la raíz antropológica de la ambigüedad del capital simbólico — gloria, honor, crédito, reputación, notoriedad-, principio de una búsqueda egoísta de las satisfacciones del "amor propio" que, simultáneamente, es búsqueda fascinada de la aprobación de los demás...» (1999: 219-220)

Esto es, el deseo, la líbido, está en la raíz de nuestra eficiencia como agentes sociales; una vez que, a partir del ámbito doméstico, en primera instancia, y del escolar después, ese deseo narcisista toma en consideración a los demás, la mecánica de nuestra aprendizaje social quedará fijada a la búsqueda del reconocimiento; que es, pues, un reconocimiento deseado y primariamente afectivo pero que acabará transmutándose en una modalidad "objetivaada" de naturaleza representacional derivada de la dicotomía racionalista sujeto/ objeto que se aplica en y a las relaciones sociales en las que nos implicamos.

Nuestro conocimiento, práctico, radica en nuestras emociones, en nuestro anhelo de reconocimiento afectivo... en nuestra precariedad e indefensión constitutivas como seres humanos; pero nuestra socialización ocultará esa constitución primaria y nos involucrará en el juego especular propio de racionalidad occidental y marcará, con una nueva dicotomía, la erradicación del deseo de nuestra condición humana, separando y oponiendo la racionalidad del conocimiento de la irracionalidad del deseo, pues el deseo ha sido postulado como irracional.

Ahora bien, cuando asumimos que nuestro conocimiento no es únicamente, y quizá tampoco principalmente, racionalidad, cuando asumimos su condición creativa, sus potencialidades transductivas y autobservacionales, cabe entonces reintegrar el deseo, las emociones, al lugar central que de hecho ocupan en nuestra condición de seres humanos y de agentes sociales.

Cuerpo y emociones van de la mano, son una y la misma cosa, relegados al ostracismo, a la inferioridad a lo no propiamente humano de nuestra constitución como seres humanos por la cultura racionalista que nos impone esa abstracción del sujeto. Y por ello, siendo el cuerpo (animalidad, biología, adiestramiento, entrenamiento, estética, ademanes, posturas, vestimenta...) el objeto de intervención por excelencia de los mecanismos de dominación a los que estamos sujetos (sujetos sujetados, diría Jesús Ibáñez), las emociones son el vehículo a través del cual operan dichos mecanismos. Para una adecuada conformación de las colectividades ciudadanas - adecuada para los intereses de los conformadores, claro está- es necesario movilizar emocionalmente los cuerpos que constituyen, de hecho y humanamente, dichas colectividades. 
Pero dicha movilización será ocultada mediante discursos de legitimación que los poderes constituidos elaboran al amparo de discursos científicos, discursos pretendidamente de verdad que lo son, de hecho, de poder.

"Fumar perjudica seriamente la salud", según avala el discurso médico, como verdad puesta al servicio de los poderes públicos, se realiza de hecho mediante una sistemática recomposición corporal de la ciudadanía (expulsión de espacios, intervenciones clínicas para "curar" la adicción y proscripción normativa de lo que, de hecho, es un acto corporal), y se hace inculcando la culpa, la vergüenza, el propio descrédito (por débiles, pusilánimes si no pueden dejar el "vicio") en los cuerpos adeptos al acto, y el odio, la imprecación, el desprecio, en las supuestas "víctimas" del acto, que como tales lo son porque sus cuerpos están en riesgo.

Somos cuerpos emocionados, permanentemente, mucho más que sujetos racionales; ésa es la condición principal de nuestra existencia social y el fundamento de nuestras prácticas cotidianas: la frustración del científico y el sufrimiento del dis-capacitado son los fundamentos, reales, de una Tesis Doctoral y de un Proyecto Docente y de Investigación, que, como tales, se sitúan en el terreno abstracto de la formulación académica (son textos) pero radican, como práctica que los propicia en su procesualidad, en la existencia concreta, corporal y emocional, de quien los lleva a cabo; y por eso, en el plano de la abstracción académica (reflexividad y autobservación) se ponen en cuestión las ortodoxias racionalistas que niegan esa condición vital, corporal, emocional, que los define en su verdadera naturaleza constitutiva.

Como diría Bourdieu, conocer es disponer de un cuerpo bien adiestrado para desenvolverse en el mundo social y, al hacerlo, la razón que guía sus actos es la de esa pulsión primaria narcisista transmutada en búsqueda de reconocimiento, la canalización social-corporal del deseo.

Es por eso que, naturalmente, no se puede entender la trayectoria que configura y propicia la presente fundamentación sin tomar conciencia y hacer expresos esos hondos malestar e insatisfacción (digamos que con el mundo en su conjunto; probablemente por la razón egoísta y pasional de no sentir el reconocimiento en pos del cual se va) de los que vitalmente surge; la dimensión pulsional, emocional, instalada en la base de tal trayectoria ${ }^{11}$. Dimensión que se transmuta en la concepción de que el mundo (social) es manifiestamente mejorable y que la labor del investigador social es suministrar cuantas herramientas pueda a sus pobladores/as para llevar a cabo, de hecho y en la práctica, esa mejora (una mejora, claro está, definida, condicionada y orientada por unas determinadas preferencias ideológicas, tan arbitrarias como cualesquiera otras posibles que dictaminarían muy distintas preferencias de mejora).

\footnotetext{
${ }^{11}$ Uno de los miembros de la comisión, sabiamente, tuvo a bien utilizar el calificativo "osco" (educadamente suavizado con el paliativo "un tanto") para indicar el tono y el proceder habitual de quien esto escribe. Dado que el comentario se inscribía en un elogio a los resultados de dicha osquedad, anticipaba, con ello, lo que aquí se trata de constatar: la condición eminentemente emocional de una actividad académica. Si las condiciones materiales de existencia determinan la conciencia (y asumo como cierta la afirmación), también lo hacen, probablemente en igual medida, las condiciones emocionales de existencia; así como el cuerpo que las porta.
} 
Estamos, pues, ante una fundamentación que, bajo los criterios de la reflexividad transductiva y la autobservación, como mecanismos antiobjetivistas y anti-racionalistas de procedimiento, lo es de un cuerpo con discapacidad insatisfecho vitalmente con el mundo que, a la par, habita (corporal y emocionalmente) y trata de aprehender con dichas herramientas. Un mundo (social) en el que el cambio social, la discapacidad y el cambio social que define y caracteriza a la discapacidad adquieren un sentido (sentido práctico, comprometido) determinado en virtud de su particular posición en él.

\section{Una tentativa de reformulación ontogenétia}

En Del algoritmo al sujeto, afirma Jesús Ibáñez: «El camino transductivo es una (re)construcción permanente del método o meta camino a lo largo del camino, por un sujeto en proceso que sigue al ser en su génesis, en su incesante producción de nuevas estructuras» (1985: 264); procesualidad, ser y génesis como delimitaciones metodológicas de la transducción. Estamos hablando de cambio social; lo cual resultará más evidente si apelamos a la fuente de la cual Ibáñez toma el concepto transducción: Gilbert Simondon.

Simondon, en La génesis del individuo ${ }^{12}$, propone el concepto de transducción para interpretar la categoría «individuo» desde una perspectiva crítica respecto de las concepciones tradicionales, tanto substancialistas como hilemórficas, pues otorgan un «privilegio ontológico al individuo ya constituido». Este privilegio conduce a concebir la génesis del individuo como una ontogénesis a la inversa, puesto que al dar por presupuesto al individuo se acepta la existencia de un primer término que, por desarrollo, conducirá a su plena realización como individuo, y así. éste puede llegar a ser entendido a través de ese proceso evolutivo. El presupuesto condiciona la necesidad de explicar el proceso que conduce a él como resultado.

Hemos de invertir nuestro modo de ver las cosas, abandonar ese privilegio ontológico y centrar nuestra atención en el proceso mismo que conduce al individuo como conclusión: «...existe una región de incertidumbre a la hora de ocuparse del proceso de individuación, porque este proceso se considera como algo que necesita ser explicado, no como algo donde se va a encontrar la explicación» (p. 257), mientras que de lo que se trataría sería de «...entender el individuo desde la perspectiva del proceso de individuación en lugar del proceso de individuación por medio del individuo» (Ibíd.)

Se trata, en consecuencia, de otorgar privilegio a la procesualidad a través de la cual se constituye el individuo, de entenderlo en virtud de su génesis y no a la inversa, puesto que ese punto de llegada pudiera no ser definitivo y pudiera no agotar todas las posibilidades contenidas en el proceso que le da origen. El proceso implica dos condiciones que, en última instancia, habrá que considerar, no como dimensiones contextuales asociadas al individuo, sino como ingredientes constitutivos del mismo; implica un medio e implica un devenir. Es decir, el proceso de individuación genera la díada individuo-medio (y no únicamente al individuo en un medio dado) y define el devenir como una

12 Simondon (1996); en Crary, J. y Kwinter, S. (eds.): Incorporaciones, Madrid, Cátedra; pp. 255-276. 
condición de su existencia. ${ }^{13}$ De este modo, tal cual ha sido concebida hasta ahora, la categoría individuo no abarca todas las condiciones efectivas de su constitución, de tal modo que la ontogénesis que lo explicaría como resultante pleno de una evolución previa, lo hace según una lógica que no traduce ésa su constitución, sino tan sólo un «estado» relativo de su existencia: el individuo no responde al principio de la unidad ni al de la identidad, debido a ésa su procesualidad constitutiva. ${ }^{14}$

Por lo tanto, si concebimos al «ser social» bajo las categorías que nos definen a un individuo «incompleto», no accederemos a su sentido integral. Ese tipo de lógica interpretativa es el que ha impedido considerar la dimensión reflexiva del ser social en su sentido constitutivo, en su sentido transductivo. Para rescatar ese sentido, habremos de desvelar las condiciones fundamentales de su constitución, los parámetros a partir de los cuales situarnos en la plena comprensión de su génesis. Las hemos anticipado ya; ahora tratamos de reconstruirlas desde esta perspectiva ontogenética. Esas condiciones nos revelan a un individuo que es sujeto-agente (y no únicamente "sujeto"), pues piensa y actúa de manera simultánea e indisociable, alterando recíproca y constantemente esa su doble constitución cognitivo-activa. Para entender esta dualidad, hemos de presuponer, además de un substrato físico-biológico, uno psíquico (fundamento ontológico de la dimensión cognitiva) y otro relacional (fundamento ontológico de su dimensión activa). La categoría individuo que propone Simondon abarcaría los cuatro niveles (físico; biológico; psíquico y social), de entre los cuales, los dos últimos son los fundamentales desde una perspectiva sociológica: la existencia de lo social requiere necesariamente de actores en interacción y de conciencia orientada en y hacia esa interacción.

Podemos traducir esto diciendo que, tanto los fundamentos positivistas de Durkheim, como los comprensivos de Weber son condición necesaria para la existencia de lo social. Pues efectivamente existen «hechos sociales» observables, materializados en conductas explícitas, en registros o códigos, y en objetos; pero también existen referentes simbólicos y comunicacionales colectivos en virtud de los cuales el sentido de dichos hechos sociales adquiere homogeneidad para sus protagonistas e intérpretes. ${ }^{15}$ Los hechos sociales se

${ }^{13}$ El individuo «tiene una realidad relativa, que ocupa sólo cierta fase del ser en cuestión (...) no agota en el acto de su aparición todos los potenciales del estado preindividual. La individuación, además, da lugar, no sólo al individuo, sino a la díada individuo-medio» (p. 258); y «...el devenir existe como una de las dimensiones del ser, que corresponde a una capacidad que los seres poseen de desfasarse respecto de sí mismos» (pp. 258-59)

${ }^{14}$ En esa procesualidad hemos de presuponer la «...supersaturación inicial del ser, al principio sin devenir y luego adoptando cierta estructura y devenir» (p. 259), supersaturación que no sería reductible a las categorías lógicas tracionales; el ser es un «sistema tensamente extendido y supersaturado que existe en un nivel superior a la unidad misma (...) La unidad y la identidad son aplicables sólo a una de las etapas del ser, que viene después del proceso de individuación (...) no tiene validez para explicar la ontogénesis en el sentido total del término» (Ibíd.).

${ }^{15}$ Curiosamente, esta doble necesidad, desde perspectivas tan dispares, conduce en uno y otro caso a la asunción de un principio de imposición: para Durkheim, los hechos sociales perduran en virtud de su imposición coactiva; para Weber, la acción social reproduce organizacionalmente siempre una lógica de dominación en la que su sentido es aplicado mediante el poder. El contexto social implica que no todos los actos son posibles ni todos los sentidos aplicables a ellos. Lo cual, hasta cierto punto, ilustra esa incompleción del individuo como categoría según se la ha entendido tradicionalmente: ambos autores reconocen 
inscriben en las mentes de los actores (sujetos-agentes) como normas morales, tanto como patrones de sentido para la interacción y la comunicación.

Ahora bien, hemos de prestar también atención al substrato biológico, pues su especificidad implica ya ciertas condiciones que van a ser de fundamental importancia en el nivel psico-social. El ser vivo ya no puede ser entendido como producto evolutivo de una herencia genética previa, sino que ha de ser interpretado en términos radicalmente procesuales: es, en sí mismo, una actividad de individuación permanente. Y no se manifiesta de manera mecánica resolviendo problemas adaptativos, sino que ese proceso de individuación permanente que supone engendra novedad, es un proceso creativo: «El ser vivo resuelve sus problemas, no sólo adaptándose (..), sino también modificándose a sí mismo mediante la invención de nuevas estructuras internas» (p. 262). Es decir, contiene en sí esa recursividad creativa que señalábamos como condición de la reflexividad constitutiva. Esa capacidad autogenerativa nos indica ya un proceso dotado de historicidad, en el sentido de que el individuo vivo queda marcado por su biografía, introyecta su pasado haciéndolo constituyente activo de su devenir, consolidando un «interior» activo que es la manifestación, en este substrato biológico, de la creatividad psíquica. Es decir, el interior del ser vivo adquiere un papel constitutivo (papel que sólo ejerce la frontera en el mundo inorgánico: el proceso de individuación del cristal nos lo muestra): «...todo lo que se encuentre en el interior en términos topológicos ha de concebirse como algo anterior genéticamente», mientras que «el individuo físico (...) contiene un pasado que es radicalmente "pasado"» ( $p$. 263).

Es precisamente esta generatividad interior la que sostiene la dinámica del proceso, la que nos indica que la individuación no llega a término, pues ese interior es un potencial permanentemente actualizable, un pasado o herencia constituyente del individuo presente: «el individuo finalmente constituido lleva cierta herencia asociada a su realidad preindividual (...) Existe cierto nivel de potencial que perdura, lo que significa que siguen siendo posibles más individuaciones» (p. 263). El ser vivo está dotado de memoria; y es la memoria la que, genéticamente, posibilita su condición creativa y autotransformadora.

Dada esta condición procesual permanente, ya no es posible, tampoco a este nivel biológico, concebir lo relacional como una mediación entre términos establemente constituidos y definitivamente configurados; lejos de ello, lo relacional está inscrito en el proceso mismo que es el individuo (recordemos que la individuación genera la díada individuo-medio) «La relación no surge entre dos términos que son individuos ya separados, sino que es un aspecto de la resonancia interna de un sistema de individuación» (p. 263). Es decir, en el individuo, como proceso permanente de individuación, está presupuesto el otro, en un sentido amplio, lo que indica la necesidad de adquirir una «frecuencia»

implícitamente que hablan de uno de los múltiples estados posibles de nuestra existencia colectiva, aquél en el que el individuo ha adquirido ciertos referentes normativos (y no otros cualesquiera) y ciertas capacidades comunicativas e interpretativas (y no otras cualesquiera). Se justifican sus propuestas, según el planteamiento de Simondon, por haberse adscrito al presupuesto del individuo ya constituido, la sociedad capitalista, y haber tratado de entenderlo a través de su proceso de individuación (para Durkheim, la división del trabajo; para Weber, la racionalización). 
adecuada para participar genéticamente de un proceso más amplio que lo excede como individuo.

No obstante, a este nivel biológico, es imposible hablar de reflexividad: el interior creativo no está dotado de las estructuras simbólicas necesarias, las que permiten, no sólo introyectar el pasado como elemento constituyente del proceso de individuación, sino de proyectar un reflejo, una representación (conciencia) que traduzca a nivel mental la indisociabilidad individuo-medio: sólo cuando ese otro genérico es concebido, tanto como parte del individuo, como medio de su proceso de individuación, sólo cuando el individuo se proyecte en el medio que, simultáneamente, está siendo generado en su proceso de individucación, sólo cuando el interior biológico constituyente adquiera la capacidad de representación, sólo entonces surgirá uno de los dos ingredientes esenciales de la reflexividad: «La psique representa el esfuerzo continuo de individuación de un ser que tiene que resolver su propia problemática implicándose en tanto que elemento del problema mediante su acción como sujeto» (pp. 263-64). Es decir, la psique surge como condición práctica de la individuación, no implica la adquisición de una capacidad introspectiva, sino de un recurso para resolver operativamente la problemática constituyente del proceso a través del cual el individuo transita hacia su constitución. En la misma génesis de nuestra capacidad de reflexión (ingrediente cognitivo de la reflexividad constitutiva) está implicada su naturaleza práctica.

Emerge, pues, como condición de la práctica de un sujeto implicado en la resolución de su proceso de individuación, el nivel psíquico. La combinación del substrato biológico y del psicológico determinan un individuo en proceso permanente de individuación, implicado en una práctica procesual, dotado de un interior creativo que genera soluciones novedosas derivando nuevas estructuras (de pensamiento y de acción), a partir de las que determinan la problemática a resolver. Este sujeto individual es un individuo permanentemente inconcluso y permanentemente implicado en la acción resolutoria que constituye su devenir; devenir que es ingrediente, a su vez, constitutivo de su condición de individuo; tenemos un «sujeto en proceso», dotado de la capacidad de reflexión. Pero la reflexividad social requiere de un colectivo de sujetos en proceso, todos ellos implicados en ese particular proceso de individuación; este requerimiento, además, puede considerarse una condición necesaria de cada proceso de individuación particular, pues el nivel psíquico, de modo aislado, no es suficiente para garantizar la resolución como individuo del proceso: «...el ser psíquico no es capaz de resolver su problemática particular dentro de su propia órbita. Su herencia de realidad preindividual permite que la individuación colectiva —que desempeña aquí el papel de las condiciones previas de la individuación psíquica-contribuya a la resolución, al tiempo que esta realidad preindividual es individualizada como ser psíquico que supera los límites del ser individuado y que lo incorpora a un sistema más amplio del mundo y del sujeto. La individuación en su aspecto colectivo crea un grupo individual —asociado al grupo por medio de la realidad preindividual que lleva dentro de sí, que lo une a todos los demás individuos-; lo individúa como unidad colectiva. Ambas individuaciones, la psíquica y la colectiva, tienen un efecto recíproco. Nos permiten definir una categoría transindividual...» (p. 264) 
Nos encontramos aquí con un presupuesto de crucial importancia en la constitución de un pensamiento sociológico, una teoría sociológica moderna: la socialidad es una condición natural del ser humano. No cabe considerar la existencia de un ser humano en ausencia del vínculo social; no cabe la emergencia de un sujeto individual sin la presencia de un colectivo de referencia, de un contexto de convivencia que le dote de todo cuanto permitirá su constitución como individuo. Lo social es condición necesaria para la existencia de la persona: «La unidad colectiva proporciona la resolución de la problemática individual, lo que significa que la base de la realidad colectiva forma ya parte del individuo en forma de realidad preindividual» (pp. 264-65).

Desde esta perspectiva ontogenética, el colectivo adopta un doble papel constituyente: es, a un tiempo, condición inicial necesaria como substrato común a todos los miembros del colectivo (la realidad preindividual compartida) y condición práctica de la verdadera individuación psíquica como proceso, o lo que, tradicionalmente, podría considerarse como contexto de desarrollo (la «realidad preindividual es individualizada como ser psíquico que supera los límites del ser individuado y que lo incorpora a un sistema más amplio del mundo y del sujeto»). En esta doble condición se asienta la fundamentación ontogenética de la reflexividad social: no podemos hablar de un nivel psíquico y otro social, como planos independientes del desarrollo del individuo; hemos de considerar un nivel psico-social recíprocamente condicionado en un proceso de individuación que genera la díada individuo-medio: el proceso de individuación, a nivel psico-social, genera una «categoría transindividual»; y es en esta dualidad psico-social en la que se asienta la dualidad cognitivo-práctica de la reflexividad transductiva; pues lo psíquico no es fundamento de un nivel cognitivo puesto en práctica en un contexto social, sino, a la inversa, condición práctica para la resolución del proceso de individuación adoptando la posición de un sujeto (social, anclado en una realidad preindividual compartida con los demás).

Una vez planteadas las condiciones ontogenéticas del proceso de individuación, Simondon reclama la necesidad de un cambio de método, pues la constitución del individuo no se reduce a una resolución parcial determinada en su naturaleza por las categorías epistemológicas tradicionales: el individuo, como proceso y como díada, se excede a sí mismo, se desfasa, se reestructura, se resuelve permanentemente como problemática de manera nunca definitiva. Ante esto, se requiere un «postulado de naturaleza ontológica»: «Los principios de tercio excluso y de identidad son inaplicables en el nivel del ser (...); sólo se aplican al ser después de que la individuación haya tenido lugar y se refieren a un ser bastante disminuido debido a que ha sido dividido en medio e individuo» (p. 268). Este requisito ya lo habíamos anticipado en términos epistemológicos; la perspectiva ontogenética lo traduce en términos de un fundamento ontológico para la construcción de un nuevo método.

Sobre esta premisa, Simondon nos propone un nuevo concepto, cuya definición perfila reintegrando las categorías previamente anticipadas:

«la transducción (...) denota un proceso (...) en el que una actividad se pone gradualmente en marcha, propagándose. (...) La transducción se produce cuando hay actividad, tanto estructural como funcional (...). Es la 
aparición correlativa de dimensiones y estructuras en un ser en estado de conflicto preindividual (...). Los términos últimos a que este proceso transductivo llega finalmente no existen previamente a este proceso. (...) En el campo del conocimiento traza el curso real de la invención (...) que corresponde a un descubrimiento de las dimensiones según las cuales se puede definir una problemática. Es el proceso analógico en la medida en que es vago. (...) se aplica a todos los casos en los que se produce una individuación que revela la génesis de una red de relaciones basadas en el ser. (...) Objetivamente, nos permite considerar las condiciones previas sistemáticas de la individuación, la resonancia interna y la problemática psíquica. (...) La transducción (...) es (...) también una intuición (...) que deriva la estructura resolutoria de los mismos conflictos que hay en el campo (...). El orden transductivo conserva todo lo concreto y se caracteriza por la conservación de la información» (pp. 269-71)

Esto es, la génesis del individuo, la ontogénesis social de la reflexividad constitutiva es transductiva, lo cual significa (entendido ello a partir de los presupuestos previos, lo cual significa un cambio semántico de los conceptos): procesual, expansiva, conflictual, imprevisible, analógica, relacinal, intuitiva y concreta. Esto implica que su traducción formal en términos epistemológicos no es tarea que disponga todavía de las categorías adecuadas. Ahora bien, el punto de partida está definido; no podemos adoptar una perspectiva en la que lo social se considere como mera relación entre individuos independientes en un contexto dado, ni que presuponga que su conocimiento implica operaciones abstractas que mantengan inalteradas las condiciones previas: «...es preciso revisar el concepto de relación adaptativa del individuo a su medio y también el concepto crítico de relación del sujeto que conoce con el objeto conocido» ( $p$. 265). Los individuos sociales son relaciones y su conocimiento implica (como relación, a su vez, social) una perturbación de su proceso propio.

Asumiendo esta perspectiva transductiva rompemos, de partida, con la dicotomía racionalista fundacional que sitúa al cambio social en oposición al estatismo estructural, por una parte, y con la que, correlativa, indisociable y paradójicamente estipula la dimensión estructural del cambio social por oposición a la singularidad de la actividad concreta de los agentes sociales. Cambio social indica procesualidad multidimensional: física, biológica, psíquica y propiamente social. No hay «individuo» del cambio social (sea el estatal de la soberanía múltiple, sea el socio-político nacional de la recomposición de conjunto de las relaciones de fuerza entre clases sociales, sea la clase revolucionaria o sea la mecánica de la racionalización), hay un proceso de individuación permanentemente inconcluso que implica la relación individuomedio (un medio cultural, histórico, a determinar en cada fase de esa procesualidad). Lo social es constitutivamente cambio, esto es, procesualidad generativa $y$, en ocasiones, dicha procesualidad hace emerger recomposiciones de conjunto de la díada individuo-medio: transmutaciones en los cuatro niveles del proceso de individuación que activan el interior-memoria del nivel psíquico generando prácticas colectivas hacia el exterior-proyecto (deseo) en el nivel propiamente social.

Parafraseando a Bourdieu, los campos sociales, en un determinado momento histórico, en su constitución efectiva y concreta, estructural, son el resultado de 
las acciones previas de los agentes involucrados en el mismo: un campo es la historia que lo hace ser como es. Y, paralelamente, esa estructura, como tal, no es sino la resultante relacional de las distintas posiciones relativas de dichos agentes, implicados en la competencia por el capital específico en cuestión del que se trate. $Y$ además, la eficiencia de dichos agentes viene dada porque han incorporado las dimensiones estructurales del campo, el nomos, las regularidades, y aplican categorías (no racionales, prácticas) de percepción, comprensión y acción que son resultado de y, por tanto, tienden a reproducir, dichas regularidades. En esa dinámica, modificaciones no planificadas, imprevisibles (pero, en cualquier caso, resultado de acciones de agentes determinados) pueden provocar "desfases", situaciones en las que las aptitudes prácticas adquiridas, fruto de la incorporación de un habitus alimentado por la situación previa del campo social, se manifiestan discordes, inoperativas, no conformes, con la nueva situación. Entonces se pone en suspenso la habilidad práctica. En estas situaciones se hace más manifiesto, menos "encubrible", quienes son los dominantes y quienes los dominados; la actitud más habitual es la resignación, puesto que los discursos de legitimación (eminentemente racionales), pese a todo, siguen gozando de una gran parte de su eficacia. Pero se dan las condiciones para que se produzca una respuesta, para que los dominados decidan actuar al margen de los dictados prescritos. Para ello, cree Bourdieu, es necesario que los agentes sociales activen aquello que no necesitan activar cuando la mecánica de conjunto hace que su eficiencia práctica funcione: su creatividad intelectual. Lo que, en lo que aquí se trata de exponer, quiere decir, su capacidad transductiva.

El cambio social, no ya en su dimensión constitutiva como procesualidad que caracteriza a lo social, sino en esos momentos puntuales de máxima eclosión, resulta de la aplicación de las habilidades creativas de intelectos en situación de desfase. No hay "proyecto" en ello, puesto que la emergencia de estas situaciones desencadena la activación, en el nivel psico-social del proceso de individuación en el que permanentemente se haya involucrada toda colectividad humana, de las potencialidades ya contenidas en el mismo, y una "colectivización" de esa creatividad que se plasma de modo práctico en forma de "acción social colectiva", con todas las complejidades e incertidumbres que ello conlleva. Sus protagonistas nunca saben, nunca pueden saber, a dónde les está conduciendo aquello que han puesto en marcha. Pero lo han puesto en marcha, y lo han hecho en forma de "acción social".

De este modo, ese proceso de individuación físico-bio-psico-social que constituiría la procesualidad de lo social y del cambio social hace emerger dos factores determinantes: la persona humana y la temporalidad. Pues el ser humano es, a su vez, un proceso de individuación físico-bio-psico-social, y su temporalidad propia es la de una biografía-memoria y un futuro-deseo que "colapsan" en un presente-acción. Desde la óptica que nos interesa, esto es, la de la persona humana como agente determinante del cambio social, hemos de integrar esa metaestabilidad que, según Simondon, definiría su condición de proceso de individuación; atender a los cuatro niveles. Y, evidentemente, en los niveles físico y biológico, tenemos un cuerpo, mientras que en los psíquico y social tenemos intelecto y emociones (deseos, expectativas, preferencias, ideologías, sensaciones, etc.). 
Para comprender el cambio social es necesario dar cuenta de la procesualidad que afecta corporal, emocional, cognitiva y prácticamente a los agentes sociales que son partícipes del mismo. Dichos agentes están dotados de un substrato físico y biológico y de una constitución psíquica y social, que marcan, de antemano, los límites de su capacidad de acción como agentes sociales. En un contexto cultural determinado y en un momento histórico dado, ese substrato y esa constitución serán de determinada manera y podrán indicar la potencialidad de una agencia social colectiva propiciatoria de una transmutación de conjunto de los parámetros vigentes, que lo serán, a su vez, fruto de las capacidades puestas en práctica por dichos substrato y constitución.

Y además, habrá que no olvidar que el substrato físico y biológico no es la parte mecánica, natural, neutra, que nos conforma como agentes sociales, sino que estará conformada, en su sentido y en las prácticas a él vinculadas, con los niveles psíquico y social. Somos materia y somos cuerpo, pero como materia y como cuerpo nos entendemos, asumimos y desenvolvemos socialmente según las convenciones sociales que regulan esa nuestra condición material y animal (y a fecha actual podemos modificar substancialmente la "naturaleza" física y biológica que nos constituye como cuerpos; y lo haremos, si lo hacemos, guiados por esas convenciones. Somos una totalidad en proceso permanente de redefinición).

Nada mejor para situar la cuestión que la "efervescencia colectiva" de la que hablaba Durkheim. Eso que el autor enunciaba como momentos de máxima exaltación colectiva que propiciarían (hago una lectura bastante poco fiel a la fuente) tanto la unánime ratificación de un orden normativo dado como la ruptura del mismo y la emergencia de uno nuevo, requieren de una masa humana congregada ritualmente en una práctica concreta; esto es, requiere cuerpos emocionados. Cuerpos liberados de las constricciones propias de la convencionalidad de una vida reiterativa sujeta a regulaciones dictadas, en su proceder correcto, por los poderes instituidos, mediante discursos de legitimación, que suden, griten, se comuniquen sin apelar a un discurso argumental y desencadenen, a través de esa congregación "animal", las emociones que los atraviesan. La agencia humana del cambio social es "disipativa". Como decía Freud, la líbido es de naturaleza energética y pugna siempre por descargarse de esa energía; las constricciones culturales son mecanismos de represión de la líbido, dispositivos de condensación de energía; el cambio social, en su sentido más significativo, surge cuando la presión llega a un punto que hace necesaria una liberación de conjunto.

En el nivel social del proceso de individuación es en dónde se generan todas las constricciones que tratan de modular de determinada manera (arbitraria y siempre sujeta a intereses particulares, históricamente cambiantes) la propia procesualidad. A partir de ese nivel, desde la modernidad, se han tratado de eludir los niveles físico y biológico en términos cognitivos, a la par que han sido los focos principales de intervención práctica. El ser humano ha sido reducido a un puro nivel psíquico en su formulación racionalista, siendo, a su vez, la psique reducida a cognición. El "sujeto" de la modernidad es racional, y, como tal, sujeto (sujetado) a las obligaciones morales y políticas de la ciudadanía parlamentaria representativa; un sujeto dotado de racionalidad y de responsabilidades políticas; el "individuo" moderno (ese presupuesto dado, 
según Simondon, que ya predefiniría la explicación genética que daría cuenta de él), un ser psíquica y socialmente conforme al status quo de la época. Su condición material y animal habrían sido erradicadas de su definición como sujeto-individuo; y, puestas al margen, habrían sido objeto fácil de manipulación por los poderes que avalaban, promulgaban e imponían ese discurso. Tenemos al Foucault que nos habla de la génesis de la psiquiatría o de la higiene sexual burguesa para evidenciar esa contraparte práctica del discurso del sujeto-individuo que, obviando el cuerpo en su argumentación, lo hace principal protagonista de sus intervenciones prácticas.

Ese presupuesto se anuda a otro, otro "individuo" de la Modernidad: el Estadonación. El sujeto-individuo moderno lo es de un orden político determinado, es un ciudadano, es "democrático"; no puede asumir la arbitrariedad indemostrable de un Dios incognoscible que, a través de la fe, dictamina el linaje de los que mandan; está llamado a tomar parte activa y decisoria, a "elegir" al poder. Pero sólo puntualmente.

Ahí tenemos, en su formulación concreta, los dos "individuos" que propician las dicotomías sobre las que se constituye la ciencia sociológica: la oposición individuo-sociedad es, en realidad, la oposición sujeto-individuo-ciudadano I Estado-nación democrático parlamentario representativo. Esas categorías se han elevado a condición universal (la historia de la humanidad las venía gestando desde sus inicios porque era lo que "naturalmente" habría de llegar algún día) y ha generado toda la innumerable cantidad de dicotomías sobre las que dicha ciencia se ha ido edificando a lo largo de siglo y medio.

¿Qué se perdió en el camino? Se perdió al ser humano en su integridad como tal y, con ello, la integridad de unas dinámicas colectivas que lo tienen como protagonista ineludible. A mi modesto modo de ver, para resituar nuestra concepción del mundo en el que vivimos, es necesario rescatarlo.

Y lo es para la comprensión, ajustada a las premisas que aquí se expresan, del cambio social. Y por eso entiendo que la discapacidad es un foco de atención privilegiado, puesto que lleva, necesariamente, a problematizar el concepto de ser humano que manejamos a la hora de desenvolvernos como personas involucradas en este mundo a la par que como "intérpretes" de él.

Ese sujeto-individuo-ciudadano, que en su formulación no estaba dotado de cuerpo, ni de emociones, debía cumplir otro requisito (éste no propiamente expreso en el núcleo de dicho discurso): había de ser competente económicamente. En una economía emergente, la capitalista, que en sus momentos fundacionales, reclamaba abundante mano de obra; o sea, cuerpos funcionalmente aptos para dicho desempeño. La personas con discapacidad no cumplían el requisito; suponían un "problema". Pero dado el clima ideológico de la época no se podía apelar a los métodos tradicionales (eugenesia). Había que "extirparlas" de los cauces principales de funcionamiento social que lo que estaban gestando es que, frente a la minoría capitalista propietaria, la gran mayoría proletaria trabajadora sería persona en este mundo si disponía de un medio de subsistencia económico, un trabajo con un salario.

Puesto que Dios había muerto y la Ciencia Positiva heredaba su posición de autoridad de verdad en el mundo, dado el problema, o sea, cuerpos no funcionalmente aptos para el rendimiento laboral, las personas con discapacidad fueron depositadas en sus manos: ¿solución al problema?. 
Bueno, aquí hay unos cuerpos (objeto, anatómico y fisiológico, de la medicina) no aptos para el servicio laboral. Bien; retirémoslos de la circulación, institucionalicémoslos en centres especializados y procedamos a su tratamiento. Hay que tratarlos, en su condición de no plenamente sanos (desviados anatómica y/o fisiológicamente del canon estipulado de salud), como enfermos. Curémoslos; ¿y cómo, si son incurables? Bueno, hagamos como si lo fueran: el objetivo es acercarlos lo máximo posible a ese estándar de salud que se ha estipulado.

$Y$ así ha sido el discurrir de su existencia hasta los años 60 del siglo $X X$ en el que un "agente en desfase", Ed Roberts, en EEUU, decidió "transducir" la situación, eludir ese capital simbólico del campo de la discapacidad, la promesa permanentemente incumplida de curación, asumir su condición como tal y decidir sobre su propia vida al margen de los dictámenes expertos.

La modernidad, como proceso de cambio social, transmutó severamente el proceso de individuación de las colectividades humanas que habitaban la Europa Occidental, y afectó, consiguientemente, a las vidas de las personas con discapacidad. La modernidad se ha visto sacudida en parte de sus fundamentos constitutivos, a partir de los 70, con la imposición hegemónica del neoliberalismo y la globalización; en esa mutación, precisamente, las personas con discapacidad cobraron condición de agentes sociales, desfasados, para pugnar por un cambio en sus condiciones de existencia. No cabe entender lo que les pasa sin entender la transmutación de conjunto que supuso la modernidad, en primera instancia, y la recomposición que la misma ha conocido a partir de ese giro operado a partir de los 70 . En todo caso, lo determinante es situar la agencialidad humana inmersa en ello.

Resulta que, como cuerpos y como emociones, las personas con discapacidad se escapan a los dispositivos convencionales que la modernidad ha edificado sobre la "normalidad" médicamente estipulada al respecto. Son una nota altamente discordante, incómoda. Por eso, en su existencia, colapsan el discurso racionalista de legitimación con las prácticas políticas que lo acompañan; ese discurso, en el tránsito de dos décadas (aquí en España) ha desplegado todas las medidas legislativas y normativas necesarias para suprimir la precariedad y exclusión que experimentan las personas con discapacidad; pero su eficiencia ha sido prácticamente nula porque, junto al discurso, están las prácticas disciplinarias (performativas: cine, programas de televisión, imágenes asociadas al éxito social; y conformativas: dietas, vida sana, cirugía estética, hábitos adecuados, moda, etc.) que regulan nuestra cotidianidad.

Entender el cambio social que constituye, actualmente, el fenómeno de la discapacidad, implica desentrañar el sentido que ha adquirido el "ser humano" en la modernidad, por un lado, y las prácticas de domesticación y sometimiento que, al margen de dicho sentido, se han aplicado, y se aplican, sobre el cuerpo y las emociones que, supuestamente, dicho ser humano no posee. Eso, a su vez, como espacio privilegiado de reflexión, nos permitirá desentrañar las claves definitorias del cambio social en un sentido más genérico.

Como agentes sociales (todos/as, incluidos/as los/a investigadores/as sociales), somos transductivos, capaces de creatividad práctica en un mundo contingente en el que sólo nuestras aptitudes racionales no nos sirven para 
"sobrevivir socialmente"; podemos ser, como perspectiva metodológica para asimilar dicha transductividad, autobservacionales, asumirnos conmrpmetidos/as vitalmente en esa dinámica y tratar, retrospectivamente, a partir de nuestra experiencia vital, dar cuenta de dicha transductividad. Pero, para ello, habremos de hacer expresa nuestra finitud animal, nuestra condición de cuerpos, conformados socialmente, y nuestra condicionalidad emocional, nuestra capacidad de "hacer" a partir de nuestros sentimientos. Todo ello, entendemos, define un sentido, y una práctica, de la investigación sociológica del cambio social; y, en consecuencia, de la discapacidad.

$Y$ de esta sucinta y precaria exposición se deriva, tanto formal y protocolariamente, como sustantiva y vitalmente, la fundamentación de los presentes proyectos docente y de investigación. 